\title{
Dietary fatty acids amplify inflammatory responses to infection through p38 MAP kinase
}

\section{signaling}

Sandra Rutting ${ }^{1,2}$, Razia Zakarya ${ }^{1,3}$, Jack Bozier ${ }^{1,3}$, Dia Xenaki ${ }^{1}$, Jay C. Horvat ${ }^{2}$ Lisa G. Wood ${ }^{2}$, Philip M. Hansbro' ${ }^{2,4}$, Brian G. Oliver ${ }^{1,3}$

${ }^{1}$ Respiratory Cellular and Molecular Biology, Woolcock Institute of Medical Research, The University of Sydney, Sydney, Australia;

${ }^{2}$ Priority Research Centre for Healthy Lungs, Hunter Medical Research Institute and the University of Newcastle, Newcastle, Australia;

${ }^{3}$ School of Life Sciences, University of Technology, Sydney, Australia.

${ }^{4}$ Centre for Inflammation, Centenary Institute, Sydney, NSW 2050, and University of Technology

Sydney, Faculty of Science, Ultimo NSW 2007, Australia

sandra.rutting@woolcock.org.au

razia.zakarya@woolcock.org.au

jack.bozier@woolcock.org.au

dia.xenaki@woolcock.org.au

jay.horvat@newcastle.edu.au

lisa.wood@newcastle.edu.au

philip.hansbro@newcastle.edu.au

brian.oliver@uts.edu.au

Corresponding author: Brian Oliver

Phone: (61) 9114-0367

Address: Woolcock Institute of medical research, level 3 cell biology

431 Glebe point road, Glebe, NSW, Australia, 2037 


\section{Grants}

P.M.H. is supported by a fellowship from the National Health and Medical Research Council (NHMRC) of Australia, a Brawn Fellowship from the Faculty of Health and Medicine (University of Newcastle) and funding from the Rainbow Foundation. The authors thank F. Thomson and M. Thomson for their continued support. B.G.O is supported by a fellowship from the National Health and Medical Research Council (NHMRC) of Australia (APP1110368).

\section{Disclosures}

No conflicts of interest, financial or otherwise, are declared by the authors.

\section{Author contributions}

S.R, R.Z, D.X, P.M.H, J.B and B.G.O conceived and planned the experiments. S.R. and R.Z carried out the experiments. S.R, R.Z, P.M.H, J.C.H, B.G.O and L.G.W. contributed to the interpretation of the results. S.R. took the lead in writing the manuscript. All authors provided critical feedback and helped shape the research, analysis and manuscript. 


\section{Abstract}

Obesity is an important risk factor for severe asthma exacerbations, which are mainly caused by respiratory infections. Dietary fatty acids, which are increased systemically in obese patients and are further increased after high fat meals, affect the innate immune system and may contribute to dysfunctional immune responses to respiratory infection. This study investigated the effects of dietary fatty acids on immune responses to respiratory infection in pulmonary fibroblasts and a bronchial epithelial cell line (BEAS-2B).

Cells were challenged with BSA-conjugated fatty acids ( $\omega-6$ PUFAs, $\omega-3$ PUFAs or SFAs) +/- the viral mimic polyinosinic:polycytidylic acid (Polyl:C) or bacterial compound lipoteichoic acid (LTA) and release of pro-inflammatory cytokines was measured. In both cell types, challenge with arachidonic acid (AA) ( $\omega-6$ PUFA) and Polyl:C or LTA led to substantially greater IL-6 and CXCL8 release than either challenge alone, demonstrating synergy. In epithelial cells, palmitic acid (SFA) combined with Polyl:C also led to greater IL-6 release. The underlying signaling pathways of AA and Polyl:C -or LTAinduced cytokine release were examined using specific signaling inhibitors and immunoblotting. Cytokine production in pulmonary fibroblasts was prostaglandin-dependent, and synergistic upregulation occurred via p38 MAP kinase signaling, whereas cytokine production in BEAS2Bs was mainly mediated through JNK and p38 MAPK signaling. We confirmed these findings using rhinovirus infection, demonstrating that $A A$ enhances rhinovirus-induced cytokine release.

This study suggests that during respiratory infection, increased levels of dietary $\omega-6$ PUFAs and SFAs may lead to more severe airway inflammation and may contribute to and/or increase the severity of asthma exacerbations. 
Key words: viral infection; asthma exacerbations; dietary fatty acids; primary lung fibroblasts; obese asthma.

\section{Introduction}

More than two billion people around the world are overweight or obese with a body mass index (BMI) of $25 \mathrm{~kg} / \mathrm{m}^{2}$ or more (1). This global epidemic is associated with many chronic diseases, including asthma. A number of epidemiological studies show that obesity is an important risk factor for asthma development, increasing the risk by 2.7 fold compared to normal body weight (2). However, the underlying mechanisms are still poorly understood.

Clinical studies suggest that asthma in obese individuals differs from the classical phenotype of the disease. The obese asthma phenotype is characterized by greater severity, poorer control and quality of life, and lack of atopy with neutrophilic inflammation being specifically reported in obese women (2-5). Obesity also increases the risk of exacerbations and obese patients are almost five times more likely to be hospitalised for asthma exacerbations, compared to lean patients $(3,6,7)$. Higher BMI appears to particularly increase the risk of autumn/winter exacerbations in more severe forms of asthma (6).

The major cause of asthma exacerbations is respiratory infection with rhinovirus (RV) accounting for up to $80 \%$ of all exacerbations (8). Viral-induced exacerbations in asthma are associated with increased levels of interleukin (IL)-6, the neutrophil chemoattractant CXCL8 and neutrophilic inflammation $(9,10)$. There are some studies that have reported bacterial infection to also be related to asthma exacerbations $(11,12)$, however this relationship is less evident. The impact of obesity on immune responses to infections is not clear, however obesity is associated with more severe outcomes following respiratory infection $(13,14)$. Several studies have shown associations between obesity and hospitalization and mortality following infection with pandemic influenza A/H1N1 in $2009(15,16)$. A recent study by Campitelli et al. (2014) showed that obesity increases the risk of outpatient visits following respiratory infection, compared to a normal body weight (14). The innate immune system is the first line of defence against pathogens and its aim is to rapidly clear 
the body of pathogens. To do so, the innate immune system triggers an immediate inflammatory response that induces migration and activation of immune cells into infected sites. However, an excessive inflammatory response may induce greater tissue damage than that caused by pathogens and can contribute to the cause and severity of exacerbations (8).

Obesity is the result of the continuous overconsumption of nutrients. The western diet contributes to obesity, being rich in saturated- (SFA) and $\omega-6$ polyunsaturated fatty acids (PUFAs) and low in $\omega-3$ PUFAs (17). It has been shown that the consumption of high fat meals leads to increased levels of circulating fatty acids and modulates the innate immune system, as shown by increases in the levels of CXCL8 as well as the proportion of neutrophils in the circulation and sputum $(18,19)$. Obesity itself is also associated with increased fatty acid levels (20). The serum levels of SFAs and $\omega-6$ PUFAs are substantially higher than $\omega-3$ PUFAs (21-23). $\omega-6$ PUFAs and SFAs have predominantly been associated with pro-inflammatory effects and current evidence suggests that SFAs promote inflammation through the activation of a family of receptors involved in innate immunity, known as Toll-like receptors (TLRs) (24). Several studies suggest that $\omega$-3 PUFAs have anti-inflammatory and immunosuppressive properties and may be beneficial in treating infectious diseases. $\omega-3$ and $\omega-6$ PUFAs act as bio-active molecules that are metabolized by cyclooxygenase (COX) and lipoxygenase (LOX) into prostaglandins and leukotrienes respectively, which have potential anti- and proinflammatory actions of their own (25).

An emerging hypothesis to explain why obese patients have more frequent and severe asthma exacerbations is dysfunctional innate immune responses to viral and/or bacterial respiratory infections. Increased levels of dietary fatty acids could potentially contribute to these dysfunctional immune responses.

The bronchial epithelium has always been considered as the primary site of infection. However, in vivo evidence shows infection also occurs in submucosal cells including pulmonary fibroblasts (26). This study investigated the effect of dietary fatty acids on primary human pulmonary fibroblasts (HPFs) and a bronchial epithelial cell line (BEAS-2B) in vitro, specifically examining the possible 
enhancement of respiratory infection through measuring release of inflammatory mediators involved in immune responses against infection.

\section{Methods}

\section{Cell culture}

HPFs were isolated from the parenchyma of lungs from patients undergoing lung transplantation or lung resection for thoracic malignancies, as previously described (27). Ethical approval for all experiments involving the use of human lung tissue was provided by the Sydney South West Area Health Service, and written informed consent was obtained. Table 1 shows the patient demographics. We also used the bronchial cell line BEAS-2B (ATCC, Manassas, VA). Detailed methods for culture of HPFs and BEAS2B are provided in the Online Supplements.

\section{Preparation of BSA-conjugated fatty acids}

Stock solutions of $0.5 \mathrm{M} \omega-3$ polyunsaturated fatty acids (PUFAs) (docosahexaenoic acid (DHA), eicosapentaenoic acid (EPA) and $\alpha$-Linolenic acid (ALA)), saturated fatty acid (SFA) (palmitic acid (PA)) and 0.3M $\omega-6$ PUFA (arachidonic acid (AA)) (Sigma Aldrich) were prepared in 100\% EtOH and stored at $-20^{\circ} \mathrm{C}$. Working water-soluble solutions of $10 \mathrm{mM}$ were generated by incubating the fatty acids in $10 \%$ endotoxin and fatty acid-free BSA (Sigma Aldrich), as previously described by Gupta et al. (2012) (28).

\section{Treatment of cells}

The cells were challenged with DHA, EPA, ALA, PA or AA $(100 \mu \mathrm{M})$ or vehicle (EtOH/BSA/cell culture medium) 4 hours prior to stimulation with or without the viral mimic polyinosinic:polycytidylic acid (Polyl:C) $(10 \mu \mathrm{g} / \mathrm{ml})$ or bacterial compound lipoteichoic acid (LTA) $(10 \mu \mathrm{g} / \mathrm{ml})($ Sigma Aldrich). All cells were incubated at $37^{\circ} \mathrm{C}$ with $5 \% \mathrm{CO}_{2}$ for 24 hours.

\section{Determination of IL-6,CXCL8, GM-CSF and CCL5 levels}

Levels of supernatant IL-6, CXCL8, granulocyte-macrophage colony-stimulating factor (GM-CSF) and 
chemokine ( $\mathrm{C}-\mathrm{C}$ motif) ligand 5 (CCL5) were measured using commercial ELISA kits according to the manufacturer's instructions (R\&D Systems, Minnesota, USA).

\section{Western blotting}

Total protein concentrations were obtained using a bicinchoninic acid assay according to the

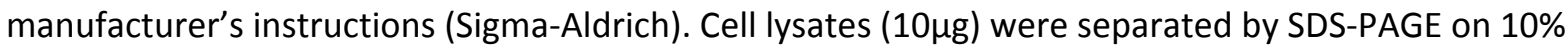
gels and transferred to PVDF membranes. The membranes were incubated with rabbit monoclonal antibodies against total and phosphorylated NF-KB p65, p38 mitogen-activated protein kinase (MAPK) or stress-activated protein kinase/c-Jun NH2-terminal kinase (SAPK/JNK) (all 1:1000, Cell Signaling Technology) and anti-mouse glyceraldehyde-3-phosphate dehydrogenase (GAPDH) (1:5000, Merck Millipore, USA). Primary antibodies were detected with goat anti-rabbit or rabbit anti-mouse horseradish peroxidase (HRP)-conjugated secondary antibodies (DAKO, USA) and visualized by enhanced chemiluminescence (Image Station 4000MM; Kodak Digital Science, New Haven, CT). GAPDH served as the loading control. Detailed methods are provided in the Online Supplements.

\section{Signaling pathway inhibition}

HPFs and BEAS-2Bs were treated with inhibitors of p38 MAPK (SB239063, $3 \mu \mathrm{M}, \mathrm{IC}_{50}=44 \mathrm{nM}$ ) (Tocris,

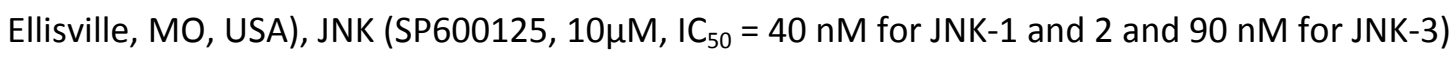
(Calbiochem, San Diego, CA), COX (indomethacin, $10 \mu \mathrm{M}, \mathrm{IC}_{50}=0.23 \mu \mathrm{M}$ for COX-1 and IC $50=0.63 \mu \mathrm{M}$

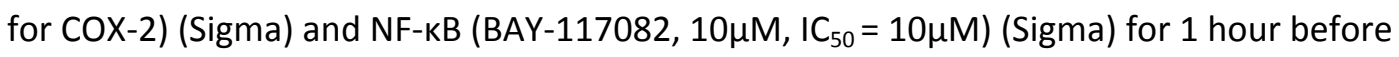
stimulation with AA $(100 \mu \mathrm{M})$ with or without Polyl:C $(10 \mu \mathrm{g} / \mathrm{mL})$ or LTA $(10 \mu \mathrm{g} / \mathrm{mL})$.

\section{Rhinovirus infection}

Major group human RV serotype-16 (RV16) was a kind gift from Prof Johnston (imperial College UK). RV16 was grown in HeLa cells and infectivity titre was determined using a titration assay as previously described $(29,30)$. HPFs were unstimulated or treated with AA $(100 \mu M) 4$ hours prior to 
infection with or without live RV16 at a multiplicity of infection (MOI) of 1. Plates were incubated at $37^{\circ} \mathrm{C}$ with $5 \% \mathrm{CO}_{2}$ for 24 hours.

\section{Statistical analysis}

Statistical analysis was conducted using GraphPad Prism version 7 software (San Diego, CA).

Comparisons of the data were carried out by one-way ANOVA with repeated measures followed by a Bonferroni post-test, where appropriate unless otherwise specified. A probability $(p)$ value of less than 0.05 was considered significant. 


\section{Results}

\section{Stimulation with AA and Polyl:C leads to greater cytokine release from fibroblasts.}

To assess if dietary fatty acids modulate the response to viral infection, HPFs were challenged with $100 \mu \mathrm{M}$ of DHA, PA or AA prior to stimulation with Polyl:C $(10 \mu \mathrm{g} / \mathrm{ml})$ and IL-6, CXCL8, GM-CSF and CCL5 release was measured. AA alone, but not DHA or PA, induced IL- 6 and CXCL8 release $(n=11$, $p<0.05)$ (Figure 1). Polyl:C alone also induced IL-6 and CXCL8 release $(n=11, p<0.05)$. Challenge with the combination of AA and Polyl:C resulted in substantially greater IL- 6 and CXCL8 release than AA alone $(n=11, p<0.01)$ (Figure $1 A$ and $1 B)$. The effect of the combination of AA with Polyl:C on IL-6 and $\mathrm{CXCL8}$ release was greater than the sum of the individual effects of AA and Polyl:C, demonstrating a synergistic effect. There was no interaction between DHA or PA and Polyl:C on IL-6 and CXCL8 release. None of the treatments induced GM-CSF release from the HPFs (data not shown). CCL5 was induced upon Polyl:C -challenge and interestingly AA and DHA suppressed Polyl:Cinduced CCL5 release $(n=5-8, p<0.05)$ (Figure 1 C and $1 F)$.

\section{Stimulation with AA and LTA leads to greater cytokine release from fibroblasts.}

To evaluate whether there is an interaction between dietary fatty acids and bacterial infection, HPFs were treated with dietary fatty acids prior to stimulation with LTA $(10 \mu \mathrm{g} / \mathrm{ml})$. LTA alone did not induce IL-6 or CXCL8 release (Figure 2). However, both IL-6 and CXCL8 release $(n=11, p<0.05)$ was greater upon challenge with the combination of AA and LTA compared to AA alone (Figure 2A and $2 B$ ), also demonstrating synergistic effects. Again, there was no interaction between DHA or PA and LTA. In addition, there was no induction of GM-CSF or CCL5 with any of these treatments (data not shown). 
$\omega-3$ PUFAs do not suppress combined AA and Polyl:C-induced cytokine release.

The $\omega-3$ PUFA DHA did not affect Polyl:C -induced IL-6 and CXCL8 release in HPFs. To confirm that $\omega-3$ PUFAs do not affect IL- 6 and CXCL8 release, we investigated the effects of the other $\omega-3$ PUFAs ALA and EPA and found that these fatty acids also do not affect the response to Polyl:C (See Supplementary Figure 1). Because nutrients do not occur in isolation, and healthy diet consists of $\omega-3$ PUFAs: $\omega-6$ PUFAs in a 1:4 ratio (31), we next investigated the effects of DHA:AA, EPA:AA and ALA:AA in a 1:4 ratio on Polyl:C-induced cytokine release. There was no difference in the response to AA with or without DHA, EPA or ALA in combination with Polyl:C (See Supplementary Figure 2), showing that $\omega-3$ PUFAs do not suppress AA and Polyl:C mediated inflammatory responses in HPFs.

Stimulation with AA and Polyl:C or LTA also leads to greater cytokine release from epithelial cells. To explore whether other structural lung cells respond similarly to HPFs, we repeated selected experiments in the bronchial epithelial cell line, BEAS-2B. AA alone did not induce IL-6 or CXCL8 release from BEAS-2Bs, however AA in combination with Polyl:C resulted in greater IL-6 release $(n=6, p<0.05)$ than Polyl:C alone (Figure $3 A$ ), showing similar responses as in HPFs. PA in combination with Polyl:C also resulted in greater IL-6 release $(n=6, p<0.05)$ than Polyl:C alone (Figure 3G). DHA did not affect Polyl:C -induced IL-6 or CXCL8 release, but suppressed Polyl:Cinduced CCL5 release $(n=7, \mathrm{p}<0.05)$ (Figure 3F). Furthermore, LTA alone did not induce cytokine release from BEAS-2BS. However, the combination of AA and LTA resulted in significant IL-6 and CXCL8 release $(n=6, p<0.01$ ) (Figure $4 A$ and $4 B$ ). There was no interaction between DHA or PA and LTA (Figure 4C-F).

p38 MAP kinase hyperactivation in pulmonary fibroblasts upon challenge with AA and Polyl:C To investigate the mechanisms underlying the effects of AA- and combined AA and Polyl:C or LTAinduced IL-6 and CXCL8 release in HPFs, we used protein immunoblotting to investigate the activation of three main signaling pathways ( $\mathrm{p} 38, \mathrm{NF}-\mathrm{KB}$ and SAPK/JNK), all of which have been 
shown to play a role in prostaglandin or infection-mediated inflammatory responses $(32,33)$. Phosphorylation of p38 MAP kinase was increased after stimulation with AA alone $(n=8, p<0.01)$ and in combination with Polyl:C $(p<0.001)$ or LTA $(p<0.01)$, while Polyl:C and LTA alone did not affect p38 MAP kinase phosphorylation (Figure 5A). The combination of AA and Polyl:C led to greater phosphorylation of p38 MAP kinase than AA alone $(n=8, p<0.05)$, indicating hyperactivation of this pathway to be the mechanism by which synergism occurs. NF-KB phosphorylation was increased upon challenge with Polyl:C $(n=8, p<0.01)$ and LTA alone $(n=8, p<0.01)$, but not in combination with AA (Figure 5B). Phosphorylation of SAPK/JNK was increased upon challenge with AA in combination with Polyl:C $(n=7, p<0.05)$, but not with any other challenge (Figure $5 C$ ). Total p38 MAP kinase, NF-KB and SAPK/JNK did not change with any treatment (Figure 5D-F).

\section{AA and Polyl:C or LTA-induced cytokine release in pulmonary fibroblasts is mediated via p38 MAP} kinase signaling. To further investigate and confirm the mechanisms underlying the effects of AAand combined AA and Polyl:C- or LTA-induced IL- 6 and CXCL8 release, specific inhibitors were used to block p38 MAPK, JNK and NF-KB activation. Inhibition of p38 MAP kinase suppressed IL-6 and $\operatorname{CXCL8}(n=9-14, p<0.01)$ release induced by AA alone (Figure 6A and $6 B)$, the combinations of AA and Polyl:C (Figure 6E and 6F) and AA and LTA (Figure 6G and 6H), but did not affect cytokine release induced by Polyl:C alone. Inhibition of JNK attenuated IL-6 release induced by Polyl:C alone $(n=10$, $p<0.0001$ ) (Figure 6C) and AA combined with Polyl:C $(n=10, p<0.01)$ (Figure 6E). Inhibition of NF-KB only suppressed IL-6 release induced by AA in combination with LTA ( $n=14, p<0.01)$ (Figure 6G).

\section{Inhibition of COX suppresses AA and Polyl:C or LTA- induced cytokine release in pulmonary}

fibroblasts. AA is a bio-active molecule and is a precursor that is metabolized by COX to produce eicosanoids, including the prostaglandins $(25,34)$. Prostaglandins are known to play a key role in the generation of inflammatory responses. To investigate whether COX-mediated prostaglandins contribute to the induction of IL- 6 and CXCL8 release, HPFs were pre-treated with the non-selective COX-inhibitor, indomethacin. We found that indomethacin $\left(10^{-5} \mathrm{M}\right)$ pre-treatment suppressed IL-6 
and CXCL8 release induced by AA alone (Figure 6A and 6B), AA in combination with Polyl:C (Figure $6 E$ and $6 F)$ and AA in combination with LTA (Figure $6 G$ and $6 H)(n=9-14, p<0.01)$. However, indomethacin pre-treatment did not affect cytokine release induced by Polyl:C alone. Inhibition of COX and p38 MAPK were the only two pathways to inhibit both AA and Polyl:C- as well as AA and LTA-induced IL-6 and IL-8 release.

\section{AA and Polyl:C or LTA-induced cytokine release in BEAS-2Bs is mainly mediated JNK and p38 MAPK} signaling. The underlying mechanisms in BEAS-2Bs were also investigated and we found that phosphorylation of p38 MAP kinase was increased 30 minutes after stimulation with AA alone, and AA in combination with Polyl:C or LTA $(n=8, p<0.05)$ (Figure 7A). NF-KB phosphorylation was increased upon challenge with Polyl:C and LTA alone, and challenge with AA in combination Polyl:C $(n=7, p<0.05)$ (Figure 7B). Phosphorylation of SAPK/JNK was increased upon challenge with AA in combination with LTA $(n=7, p<0.05)$ (Figure $7 C)$.

In addition, inhibition of p38 MAP kinase or JNK suppressed IL-6 and CXCL8 release induced by Polyl:C alone, AA in combination with Polyl:C and AA in combination with LTA $(n=7, p<0.05)$ (Figure 8). Inhibition of NF-KB suppressed IL- 6 and CXCL8 release induced by AA in combination with Polyl:C $(n=7, p<0.05)$ (Figure 8A and 8B), and CXCL8 release induced by Polyl:C alone $(p<0.05)$ (Figure $8 D)$. Inhibition of JNK resulted in the greatest suppression of combined AA and Polyl:C- or LTA-induced IL6 and CXCL8 release. Inhibition of COX did not suppress IL-6 or CXCL8 release in BEAS-2Bs. These results show that the responses in BEAS2Bs are different from HPFs and are mediated through NF$\mathrm{KB}, \mathrm{JNK}, \mathrm{p} 38$ MAP kinase, but not COX signaling and suggest JNK signaling to be the dominant pathway. 


\section{Infection with human RV16 leads to greater AA-induced cytokine release.}

To ensure that our results with pathogen components are reflective of a live infection, we next assessed if the innate immune response to RV was modulated by $A A$. RV was chosen due to its high prevalence in the community and has been shown to be a major cause of asthma exacerbations (8). Challenge with AA $(100 \mu \mathrm{M})$ in combination with RV16 infection at MOI of 1.0 resulted in substantially greater IL-6 and CXCL8 $(p<0.05)$ release than AA or RV alone from HPFs $(n=9)$ (Figure $9 A$ and $9 B)$ and BEAS2Bs $(n=7)$ (replicates) (Figure $9 C$ and $9 D)$. The effect of the combination of AA with RV16 on IL-6 and CXCL8 release was greater than the sum of the individual effects of AA and RV16 in both cell types, demonstrating synergistic effects. 


\section{Discussion}

Obese asthma patients have more frequent and severe exacerbations, which may be a result of excess dietary fatty acids enhancing the innate immune response to viral and/or bacterial infection. This study is the first to examine the effects of dietary fatty acids in this context.

This study demonstrates that the $\omega-6$ PUFA AA in combination with the viral mimic Polyl:C results in greater IL-6 and CXCL8 release than either AA or Polyl:C alone. Interestingly, the effect of the combination on cytokine release was substantially greater than the sum of the individual effects of AA and Polyl:C which indicates that these effects are synergistic. We also examined the effects of dietary fatty acids on respiratory infection in epithelial cells. Interestingly, we found that epithelial cells are unresponsive to AA alone, but the combination with Polyl:C results in synergistic cytokine release. In addition, PA enhanced Polyl:C-induced cytokine release from epithelial cells. These results show that dietary fatty acids have different effects on different lung cells and suggest that increased levels of AA and PA during viral infection may lead to more severe airway inflammation.

The current study mainly focussed on the cytokines IL- 6 and CXCL8, as these are crucial drivers of neutrophilic inflammation and are clinically important in both the pathogenesis of asthma and clinical outcomes in severe and obese asthma, including viral-induced exacerbations. However multiple cytokines and chemokines are important in driving granulocyte recruitment and activation in asthma. We also measured CCL5 (RANTES) and GM-CSF release. There was no induction of GMCSF in both cell types. However, DHA reduced Polyl:C-induced RANTES in HPFs and BEAS2Bs. In addition, AA reduced Polyl:C-induced RANTES in fibroblasts, but not BEAS2Bs. We interpret these results as further evidence that the immune response in obese asthma is skewed towards neutrophilic inflammation. If there was GM-CSF induction, this would have been evidence of a granulocytic response, since it promotes the proliferation, differentiation, and activation of monocytes, neutrophils, eosinophils and dendritic cells and act as a cofactor for superoxide production and degranulation $(35,36)$. The suppression of CCL5 (RANTES) by AA further reinforces neutrophilic inflammation as it typically recruits monocytes, $\mathrm{T}$ cells, and eosinophils and has been 
associated with eosinophilic airway inflammation in asthma $(37,38)$.

$\mathrm{RV}$ is the most common cause of virus-induced exacerbations in both children and adults with asthma $(8,39)$. In the past, RV was considered as an upper respiratory pathogen only. However, in vivo studies have conclusively shown that $\mathrm{RV}$ can also replicate in the lower airways $(26,40)$ and can infect submucosal cells which include pulmonary fibroblasts and airway smooth muscle cells. We (41) and others (42) have shown that RV infects primary pulmonary fibroblasts inducing proinflammatory mediators including IL-6 and CXCL8 (41). Fibroblasts are located within the airway submucosa where airway blood vessels are found and are therefore directly exposed to constituents of tissue fluids (plasma) including dietary fatty acids, and are likely to be key cells in driving inflammatory responses to serum derived factors. As such, this study primarily focussed on pulmonary fibroblasts.

Viruses activate the innate immune response through activation of the molecular pattern recognition TLR 3,7 and 8 (43) via the activation of specific transcription factors including NF-KB and AP-1. Polyl:C is a synthetic analogue of double stranded RNA (dsRNA) and is known to activate TLR3 (44). TLR 7 and 8 detect ssRNA, while TLR 3 detects dsRNA which occurs when ssRNA viruses, including RV, replicate (43). We used an agonist for TLR3 rather than TLR 7 or 8 based on previous studies showing that RV induces cytokines via the activation of TLR3 and not TLR 7/8 in bronchial epithelial cells. Furthermore, we have previously shown that RV-induced cytokine release in fibroblasts is replication dependent (i.e the cells are detecting and responding only to dsRNA)(41).. To confirm that AA increases RV-induced inflammation, we also assessed the response to AA in combination with RV16 infection. We found that challenge with AA in combination with RV16 infection results in substantially greater cytokine release than either AA or RV16 alone in HPFs and BEAS-2Bs.

Less is known about bacterial infections in asthma. Some bacterial pathogens are more frequently found in the airways of patients with asthma than in healthy patients (12), but their role in exacerbations is unclear. Studies have reported mycoplasmal infection in up to $25 \%$ of children with 
wheezing (11) and in $20 \%$ of asthmatic children requiring hospitalization due to exacerbations. However, not all studies confirm these findings (45). The current study also investigated the effect of dietary fatty acids on bacterial infection. To model bacterial infection, we challenged cells with the bacterial endotoxin LTA. We found that challenge with AA in combination with LTA results in greater IL-6 and CXCL8 release from pulmonary fibroblasts and epithelial cells than either alone. The effect of the combination on cytokine release was substantially greater than the sum of the individual effects of AA and LTA which indicates that these effects are synergistic. These results indicate that exposure to AA during bacterial infection may lead to more severe airway inflammation. There was no interaction between the other dietary fatty acids and LTA. Bacterial recognition is dependent on TLR 2 and 4. TLR4 mainly senses lipopolysaccharide (LPS), which is a major component of the outer membrane of gram-negative bacteria. TLR2 is the primary innate immune receptor for gram-positive bacteria. We used LTA, an important cell wall polymer found in gram-positive bacteria that has been shown to cause innate immune responses mediated through TLR2 (46).

LTA alone however, did not induce cytokine release from either HPFs or BEAS2Bs. Presumably, even though bronchial epithelial cells express toll like receptor (TLR)2, challenge with LTA is not potent enough to induce the production of IL-6 or CXCL8 in epithelial cells and a co-challenge is needed. Other studies have reported similar findings. Amstrong et al. (2004) found that LTA alone does not induce the production of CXCL8 or IL-6 (47) in bronchial epithelial cells and a low responsiveness of lung epithelial cells to LTA (small increase in CXCL8 release) was observed in another in vitro study (48).

Effects of dietary fatty acids on immune responses have been an area of interest for many years. However, there is a great deal of conflicting data. DHA and AA serve as important cell membrane components as well as precursors for biologic mediators with many effects, including numerous roles in immune function and inflammation. In general, $\omega-6$ PUFAs and SFAs have predominantly been associated with pro-inflammatory effects, whereas the $\omega-3$ PUFAs are associated with antiinflammatory and immunosuppressive effects $(25,34)$. None of the $\omega-3$ PUFAs (DHA, EPA and ALA) 
suppressed Polyl:C-induced cytokine release, or combined AA and Polyl:C-induced inflammatory responses in HPFs, suggesting that $\omega-3$ PUFAs do not have anti-inflammatory effects in these lung cells. SFAs including PA initiate innate immune responses through activation of TLR2 and 4 in adipocytes and macrophages $(24,49,50)$. These results have been replicated in human studies where within 4 hours of consumption of a high fat meal, innate immune responses are activated with increased TLR2, -4 and NF-KB activity in mononuclear and polymorphonuclear cells $(51,52)$. The non-responsiveness to PA in this study may be explained by the lack of functional TLR4 signaling in pulmonary fibroblasts. Lung mesenchymal cells do not express CD14, which acts as a co-receptor for $\operatorname{TLR} 4(53,54)$. This is also the reason why we used LTA (TLR2 agonist) and not LPS (TLR4 agonist). SFAs have been shown to inhibit virus replication in a mouse model of chronic hepatitis B infection (55), however another mouse model study showed that SFAs increase bacterial load in S. aureus infection (56). Studies looking at effects of $\omega-6$ PUFAs on inflammatory processes and infections have found conflicting data. A study in healthy men found that supplementation with $\omega-6$ PUFAs significantly increased the number of circulating neutrophils and production of LPS-induced leukotriene B4 from leukocytes. Conversely, supplementation with AA did not affect in vitro secretion of TNF $\alpha$ by peripheral mononuclear cells, nor did it affect peripheral blood mononuclear cell proliferation and natural killer cell activity (57). A study by Jordao et al. (2008) found that AA enhanced bacterial killing of Mycobacterium tuberculosis in macrophages, but increased pathogen survival in a mouse model of tuberculosis (58). In the current study a clear pro-inflammatory effect of AA on bacterial and viral infection was observed.

To understand the underlying mechanisms involved in (synergistic) AA and Polyl:C- or LTA-induced IL-6 and CXCL8 production, signaling pathways were investigated. We observed activation of p38 MAPK upon challenge with AA alone and in combination with Polyl:C or LTA. Challenge with Polyl:C and LTA alone led to increased phosphorylation of NF-KB, while challenge with the combination of AA and Polyl:C caused increased phosphorylation of SAPK/JNK. AA in combination with Polyl:C led to greater phosphorylation of p38 MAP kinase than challenge with AA alone, indicating p38 MAP kinase 
signaling to be the mechanism by which synergism occurs. We further investigated and confirmed the underlying mechanisms involved in AA and Polyl:C- or LTA-induced IL-6 and CXCL8 release using specific signaling inhibitors at concentrations previously shown to be effective in human airway cells (26-28). SB239063 is a potent and selective inhibitor of p38 MAP kinase and displays specific and high-affinity binding (IC50 = 44nM) (59). It suppressed IL-6 and CXLC8 release induced by AA alone and the combinations of AA and Polyl:C or LTA. These data suggest that AA in combination with Polyl:C or LTA activates the p38 MAPK pathway, leading to both IL-6 and CXCL8 release. Inhibition of JNK with SP600125 suppressed IL-6 release induced by Polyl:C alone and in combination with AA, but did not affect CXCL8 release. Inhibition of NF-KB with BAY- 117082 partially suppressed IL-6 release induced by the combination of AA and LTA, again indicating the involvement of multiple pathways. These results, which showed that BAY-117082 suppressed AA and LTA-induced IL-6 but not CXCL8 release while SP600125 suppressed Polyl:C- and AA/Polyl:C-induced IL-6 but not CXCL8 release, are unexpected. Previous studies have shown IL- 6 and CXCL8 transcription to be regulated by the same transcription factors: NF-KB, CREB protein, AP-1, and CCAAT/enhancer binding protein (C/EBP) (60, 61). However, it appears that in this study the dominant transcription factors regulating CXCL8 are different to those regulating IL-6 with p38 MAPK being the only common transcription factor for both cytokines.

Prostaglandins (PGs), including PGE 2 , are COX metabolites of arachidonic acid. $\mathrm{PGE}_{2}$ induces IL-6 release from bronchial epithelial cells and CXCL8 from lung mesenchymal cells $(62,63)$. To investigate whether COX-mediated prostaglandins contribute to IL-6 and CXCL8 release, we pretreated pulmonary fibroblasts with indomethacin, which inhibits both COX-1 and COX-2. Indomethacin inhibited AA-induced IL-6 and CXCL8 release alone and in combination with Polyl:C or LTA. However, indomethacin did not affect cytokine release induced by Polyl:C alone. Our data suggest that IL-6 and CXCL8 production in HPFs is prostaglandin-mediated. We consider these effects to be mediated through COX-2 rather than COX-1, as COX-1 is responsible for constitutive production under basal conditions, whereas COX-2 is upregulated during inflammation and is 
responsible for $\mathrm{PGE}_{2}$ biosynthesis at sites of inflammation (64). We consider the combination of the production of COX-mediated prostaglandins and the activation of transcription factors the most logical mechanism for synergistic cytokine release in HPFs.

We also investigated the underlying mechanisms in BEAS-2Bs and found that p38 MAP kinase signaling is involved in Polyl:C-, combined Polyl:C and AA- and combined LTA and AA-induced IL-6 and CXCL8 release in BEAS-2Bs. However, inhibition of COX did not suppress IL-6 or CXCL8 release in BEAS-2Bs, which is different from what we observed in fibroblasts. This is consistent with the lack of cytokine induction by AA in BEAS-2B. In addition, inhibition of JNK signaling resulted in the greatest suppression of combined AA and Polyl:C- or LTA-induced IL-6 and CXCL8 release in BEAS-2BS. These results suggest that there is a differential response in BEAS-2Bs compared to fibroblasts. Although the studies in this manuscript utilized primary human pulmonary fibroblasts, an important limitation of this study is that all studies were done in vitro. In future studies effects of dietary fatty acids on immune responses to infection will be investigated using an in vivo model.

In summary, this study demonstrates that exposure of HPFs and epithelial cells to $\omega-6$ PUFAs causes an amplification of the inflammatory responses to viral and bacterial components, as measured by IL-6 and CXCL8 release. In HPFs the responses were prostaglandin dependent and mediated through p38 MAP kinase signaling, whereas the responses in BEAS-2Bs were mainly mediated through JNK and p38 MAP kinase signaling, suggesting that p38 MAPK inhibitors might be effective in obese asthmatics to prevent exacerbations. In epithelial cells exposure to PA also enhances the inflammatory response to viral infection. These results suggest that during respiratory infection, increased levels of dietary $\omega-6$ PUFAs and SFAs may lead to more severe airway inflammation and might contribute to and/or increase the severity of asthma exacerbations in obese asthma patients. 


\section{List of abbreviations}

AA - arachidonic acid

ANOVA - Analysis of variance

$\mathrm{BMI}$ - body mass index

COX - cyclooxygenase

CCL5 - C-C Motif Ligand-5 (RANTES)

CXCL8 - chemokine (C-X-C motif) ligand 8

DHA - docosahexaenoic acid

GM-CSF - granulocyte-macrophage colony-stimulating factor

HPFs - human pulmonary fibroblasts

IL-6 - interleukin 6

LOX - lipoxygenase

LTA - lipoteichoic acid

$\mathrm{MOI}$ - multiplicity of infection

NF-KB - nuclear factor kappa-light-chain-enhancer of activated B cells

p38 MAPK - p38 mitogen-activated protein kinase

PA - palmitic acid

PGE2 - prostaglandin E2

Polyl:C - polyinosinic:polycytidylic acid

PUFA - polyunsaturated fatty acid

RV16 - human RV serotype-16

SAPK/JNK - stress-activated protein kinases/Jun amino-terminal kinases

SEM - standard error of the mean

SFA - saturated fatty acid

TLR - toll-like receptor 


\section{Acknowledgements}

We would like to acknowledge the collaborative effort of the cardiopulmonary transplant team and the pathologists at St Vincent's Hospital (Sydney, Australia), and the thoracic physicians and pathologists at the Royal Prince Alfred Hospital (Sydney) and Strathfield Private Hospital (Strathfield, Australia). 
Table 1. Summary of patient demographics

\begin{tabular}{|c|c|c|c|c|c|}
\hline Donor \# & Diagnosis & Age & Gender & Surgery & Experiment \\
\hline 1 & Emphysema & 61 & $\mathrm{~F}$ & explanted lung & fatty acids and bacterial/viral mimics \\
\hline 3 & BOS & 43 & M & explanted lung & fatty acids and bacterial/viral mimics \\
\hline 4 & COPD & 60 & $\mathrm{~F}$ & explanted lung & fatty acids and bacterial/viral mimics \\
\hline 5 & NSCLC & 62 & $\mathrm{~F}$ & lung resection & fatty acids and bacterial/viral mimics \\
\hline 6 & Ca adeno & 60 & $\mathrm{~F}$ & lung resection & fatty acids and bacterial/viral mimics \\
\hline 7 & Emphysema & 65 & $\mathrm{~F}$ & explanted lung & fatty acids and bacterial/viral mimics \\
\hline 8 & Healthy & 65 & M & explanted lung & fatty acids and bacterial/viral mimics \\
\hline 9 & Healthy & 41 & $\mathrm{~F}$ & explanted lung & fatty acids and bacterial/viral mimics \\
\hline 10 & COPD & 65 & M & explanted lung & fatty acids and bacterial/viral mimics \\
\hline 11 & Adeno ca & 72 & $\mathrm{~F}$ & lung resection & fatty acids and bacterial/viral mimics \\
\hline 12 & COPD & 61 & $\mathrm{~F}$ & explanted lung & $\begin{array}{l}\text { western blotting, inhibitors, } \\
\text { fatty acids and bacterial/viral mimics }\end{array}$ \\
\hline 13 & COPD & 62 & $\mathrm{~F}$ & explanted lung & western blotting, inhibitors \\
\hline 14 & Emphysema & 65 & $\mathrm{~F}$ & explanted lung & western blotting, Inhibitors \\
\hline 15 & Adeno ca & 57 & $\mathrm{~F}$ & lung resection & western blotting, inhibitors \\
\hline 16 & PAH & 57 & $\mathrm{~F}$ & explanted lung & western blotting, inhibitors \\
\hline 17 & IPF & 67 & M & explanted lung & western blotting \\
\hline 18 & Adeno ca & 76 & $\mathrm{~F}$ & lung resection & western blotting, inhibitors, RV16 infection \\
\hline 19 & Adeno ca & 64 & $\mathrm{~F}$ & lung resection & western blotting, inhibitors, RV16 infection \\
\hline 20 & IPF & 63 & $\mathrm{M}$ & explanted lung & western blotting, inhibitors, RV16 infection \\
\hline 21 & Emphysema & 59 & M & explanted lung & western blotting, inhibitors, RV16 infection \\
\hline 22 & $\mathrm{PAH}$ & 57 & $\mathrm{~F}$ & explanted lung & western blotting, inhibitors, RV16 infection \\
\hline 23 & COPD & 62 & $\mathrm{~F}$ & explanted lung & western blotting, inhibitors, RV16 infection \\
\hline 24 & $\mathrm{PAH}$ & 30 & $\mathrm{~F}$ & explanted lung & western blotting, inhibitors, RV16 infection \\
\hline 25 & Emphysema & 62 & $\mathrm{~F}$ & explanted lung & Inhibitors \\
\hline 26 & Emphysema & 59 & M & explanted lung & Inhibitors \\
\hline 27 & COPD & 56 & $\mathrm{~F}$ & explanted lung & inhibitors \\
\hline 28 & IPF & 58 & $\mathrm{~F}$ & explanted lung & inhibitors \\
\hline 29 & Emphysema & 64 & M & explanted lung & inhibitors \\
\hline 30 & NSCLC, COPD & 58 & M & lung resection & inhibitors \\
\hline 31 & IPF & 64 & M & explanted lung & inhibitors, RV16 infection \\
\hline 32 & Emphysema & 61 & M & explanted lung & inhibitors, RV16 infection \\
\hline 33 & COPD & 69 & $\mathrm{~F}$ & explanted lung & mixed $\omega-6: \omega-3$ PUFAs, ALA and EPA \\
\hline 34 & Interstitial pneumonitis & 59 & M & explanted lung & mixed $\omega-6: \omega-3$ PUFAs, ALA and EPA \\
\hline 35 & IPF & 64 & M & explanted lung & mixed $\omega-6: \omega-3$ PUFAs, ALA and EPA \\
\hline 36 & NSCLC & 71 & $\mathrm{~F}$ & lung resection & mixed $\omega-6: \omega-3$ PUFAs, ALA and EPA \\
\hline 37 & Adeno $\mathrm{ca}$ and COPD & 75 & $\mathrm{~F}$ & lung resection & mixed $\omega-6: \omega-3$ PUFAs, ALA and EPA \\
\hline 38 & IPF & 63 & $\mathrm{~F}$ & explanted lung & mixed $\omega-6: \omega-3$ PUFAs, ALA and EPA \\
\hline 39 & Squamous cell ca & 65 & M & lung resection & mixed $\omega-6: \omega-3$ PUFAs, ALA and EPA \\
\hline 40 & Adeno ca & 72 & $\mathrm{~F}$ & lung resection & mixed $\omega-6: \omega-3$ PUFAs, ALA and EPA \\
\hline 41 & IPF & 54 & M & explanted lung & mixed $\omega-6: \omega-3$ PUFAs, ALA and EPA \\
\hline
\end{tabular}

BOS: Bronchiolitis obliterans syndrome, COPD: chronic obstructive pulmonary disease, Adeno ca: adenocarcinoma, NSCLC: non-small cell lung carcinoma, PAH: pulmonary arterial hypertension, IPF: idiopathic pulmonary fibrosis, F: Female, M: Male 


\section{Figure legends}

Figure 1. Greater cytokine release with combined arachidonic acid and Polyl:C challenge, than either aloneHuman primary pulmonary fibroblasts were unstimulated or challenged with $\omega-6$ polyunsaturated fatty acid (PUFA) arachidonic acid (AA) ( $n=8-11$ ) (patients) (A-C), $\omega-3$ PUFA docosahexaenoic acid (DHA), ( $n=5-9$ ) (patients) (D-F) or saturated fatty acid (SFA) palmitic acid (PA), ( $n=3-9)$ (patients) (G-I) in 0.1\% BSA-DMEM $(100 \mu \mathrm{M})$ for $4 \mathrm{~h}$ with or without the viral mimic polyinosinic:polycytidylic acid (Polyl:C) $(10 \mu \mathrm{g} / \mathrm{ml})$ for another $24 \mathrm{~h}$. Cell free supernatants were collected and IL-6 (A, D, G), CXCL8 (B, E, H) or CCL5 (C, F, I) release was measured using ELISA. All data are represented as mean \pm standard error of the mean. All challenges are compared to control and challenges with Polyl: $\mathrm{C}$ are compared to their respective challenge without Polyl: $\mathrm{C}$ and challenge with Polyl:C alone, using a one-way ANOVA with a Bonferroni post-test. Significance is represented as $*(p<0.05), * *(p<0.01), * * *(p<0.001)$ or $* * * *(p<0.0001)$.

Figure 2. Greater cytokine release with combined arachidonic acid and LTA challenge, than either alone in Human primary pulmonary fibroblasts were unstimulated (control) or challenged with $\omega-6$ polyunsaturated fatty acid (PUFA) arachidonic acid (AA), $(n=11)$ (patients) (A, B), $\omega-3$ PUFA docosahexaenoic acid (DHA), $(n=10)$ (patients) (C, D) or saturated fatty acid (SFA) palmitic acid (PA), $(n=9)$ (patients) $(\mathrm{E}, \mathrm{F})$ in $0.1 \% \mathrm{BSA}-\mathrm{DMEM}(100 \mu \mathrm{M})$ for $4 \mathrm{~h}$ prior with or without the bacterial compound lipoteichoic acid (LTA) $(10 \mu \mathrm{g} / \mathrm{ml})$ for another $24 \mathrm{~h}$. Cell free supernatants were collected and IL-6 $(A, C, E)$ and CXCL8 (B, D, F) release was measured using ELISA. All data are represented as mean \pm standard error of the mean. All challenges are compared to control and challenges with LTA are compared to their respective challenge without LTA and challenge with LTA alone, using a oneway ANOVA with a Bonferroni post-test. Significance is represented as $*(p<0.05)$ or $* * *(p<0.001)$.

Figure 3. Greater IL-6 release with combined arachidonic acid or palmitic acid and PolyI:C challenge than either alone in BEAS-2Bs. The human bronchial epithelial cell line BEAS-2B was unstimulated (control) or challenged with $\omega-6$ polyunsaturated fatty acid (PUFA) arachidonic acid (AA) ( $n=6-7)$ (replicates) (A-C), w-3 PUFA docosahexaenoic acid (DHA) ( $n=6-7)$ (replicates) (D-F) or

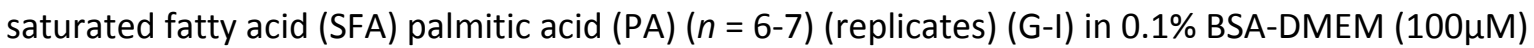
for $4 \mathrm{~h}$ prior with or without the viral mimic polyinosinic:polycytidylic acid (Polyl:C) $(10 \mu \mathrm{g} / \mathrm{ml})$ for another 24h. Cell free supernatants were collected and IL-6 (A, D, G), CXCL8 (B, E, H) and CCL5 (C, F, I) release was measured using ELISA. All data are represented as mean \pm standard error of the mean. All challenges are compared to control and challenges with Polyl:C are compared to their respective challenge without Polyl: $\mathrm{C}$ and challenge with Polyl: $\mathrm{C}$ alone, using a one-way ANOVA with a Bonferroni post-test. Significance is represented as $*(p<0.05),{ }^{* *}(p<0.01)$ or ${ }^{* * *}(p<0.001)$. 
Figure 4. Greater cytokine release with combined arachidonic acid and LTA challenge, than either alone in BEAS-2Bs. The human bronchial epithelial cell line BEAS-2B was unstimulated (control) or challenged with $\omega-6$ polyunsaturated fatty acid (PUFA) arachidonic acid (AA) $(n=6)$ (replicates) $(A, B)$, $\omega$-3 PUFA docosahexaenoic acid (DHA) $(n=6)$ (replicates) (C, D) or saturated fatty acid (SFA) palmitic

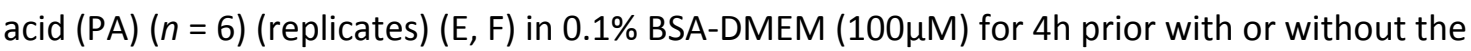
bacterial compound lipoteichoic acid (LTA) $(10 \mu \mathrm{g} / \mathrm{ml})$ for another $24 \mathrm{~h}$. Cell free supernatants were collected and IL-6 (A, C, E) and CXCL8 (B, D, F) release was measured using ELISA. All data are represented as mean \pm standard error of the mean. All challenges are compared to control and challenges with LTA are compared to their respective challenge without LTA and challenge with LTA alone, using a one-way ANOVA with a Bonferroni post-test. Significance is represented as $*(p<0.05)$ or $* *(p<0.01)$.

Figure 5. Activation of p38 MAP kinase, NF-KB and SAPK/JNK upon challenge with AA and Polyl:C or LTA. Primary human pulmonary fibroblasts $(n=7-8)$ (patients) were unstimulated (control) or challenged with arachidonic acid (AA) $(100 \mu \mathrm{M})$, the viral mimic polyinosinic:polycytidylic acid (Polyl:C) $(10 \mu \mathrm{g} / \mathrm{ml})$, the bacterial compound lipoteichoic acid (LTA) $(10 \mu \mathrm{g} / \mathrm{ml}), \mathrm{AA}(100 \mu \mathrm{M})$ in combination with (Polyl:C) $(1 \mathrm{ng} / \mathrm{mL})$ or AA $(100 \mu)$ in combination with LTA for 30 minutes, before whole cell lysates were collected and p38 mitogen-activated protein (MAP) kinase (A), NF-kB p65 (B) or JNK (C) phosphorylation was assessed by western blotting. Total p38 MAP kinase (D), NF-KB p65 (E) or JNK (F) was also assessed. All values were normalized to GAPDH (housekeeping protein), detected on the same blots. Data are expressed as fold increase of control, mean \pm standard error of the mean. All challenges are compared to control and challenges with Polyl:C or LTA are compared to their respective challenge without Polyl:C or LTA and challenge with Polyl:C or LTA alone, using a one-way ANOVA (Fisher's LSD test). Significance is represented as $*(p<0.05),{ }^{* *}(p<0.01), * * *$ $(p<0.001)$ or $* * * *(p<0.0001)$. Representative western blots of phosphorylated and total p38 MAPK, NF-KB p65 and JNK are shown under each graph.

Figure 6. Inhibition of cyclooxygenase (COX) or p38 MAPK suppresses cytokine release, induced arachidonic acid alone and in combination with viral or bacterial surrogates from fibroblasts. Primary human pulmonary fibroblasts ( $n=9-14$ ) (patients) were treated with or without the cyclooxygenase (COX) inhibitor indomethacin $\left(10^{-5} \mathrm{M}\right)$, the p38 mitogen-activated protein (MAP) kinase signaling inhibitor SB239063 $(3 \mu \mathrm{M})$, the NF-KB inhibitor BAY-117082 $(1 \mu \mathrm{M})$ or the c-Jun Nterminal kinase (JNK) inhibitor SP600125 $(10 \mu \mathrm{M})$ for 60 minutes before challenge with arachidonic

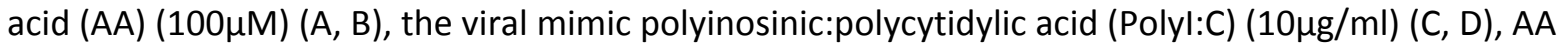
$(100 \mu \mathrm{M})$ in combination with Polyl:C $(E, F)$ or $A A(100 \mu M)$ in combination with LTA $(10 \mu \mathrm{g} / \mathrm{mL})(\mathrm{G}, \mathrm{H})$. Cell free supernatants were collected after $24 \mathrm{~h}$ and IL-6 (A, C, E, G) and CXCL8 (B, D, F, H) release was measured using ELISA. All data are represented \% cytokine release \pm standard error of the mean. All treatments with inhibitor are compared to their respective control in the absence of the inhibitor using one-way ANOVA with a Bonferroni post-test. Significance is represented as $* *$ $(p<0.01),{ }^{* * *}(p<0.001)$ or $* * * *(p<0.0001)$. 
Figure 7. Activation of $\mathrm{p} 38$ MAP kinase, NF-KB and SAPK/JNK upon challenge with AA and Polyl:C or LTA in BEAS-2Bs. The human bronchial epithelial cell line BEAS-2B $(n=4-8)$ (replicates) was unstimulated or challenged with arachidonic acid $(A A)(100 \mu \mathrm{M})$, the viral mimic polyinosinic:polycytidylic acid (Polyl:C) $(10 \mu \mathrm{g} / \mathrm{ml})$, the bacterial compound lipoteichoic acid (LTA) $(10 \mu \mathrm{g} / \mathrm{ml}), \mathrm{AA}(100 \mu \mathrm{M})$ in combination with (Polyl:C) $(1 \mathrm{ng} / \mathrm{mL})$ or $\mathrm{AA}(100 \mu \mathrm{M})$ in combination with LTA for 30 minutes, before whole cell lysates were collected and p38 mitogen-activated protein (MAP) kinase (A), NF-KB p65 (B) or JNK (C) phosphorylation was assessed by western blotting. Total p38 MAP kinase (D), NF-KB p65 (E) or JNK (F) was also assessed. All values were normalized to GAPDH (housekeeping protein), detected on the same blots. Data are expressed as fold increase of control, mean \pm standard error of the mean. All challenges are compared to control and challenges with Polyl:C or LTA are compared to their respective challenge without Polyl:C or LTA and challenge with Polyl:C or LTA alone, using a one-way ANOVA (Fisher's LSD test). Significance is represented as $*(p<0.05)$ or $* *(p<0.01)$. Representative western blots of phosphorylated and total p38 MAPK, NFKB p65 and JNK are shown under each graph.

Figure 8. Inhibition p38 MAPK or JNK suppresses cytokine release, induced by AA in combination with Polyl:C or LTA from BEAS-2Bs. The human bronchial epithelial cell line BEAS-2B $(n=7)$ (replicates) was treated with or without the cyclooxygenase (COX) inhibitor indomethacin $\left(10^{-5} \mathrm{M}\right)$,

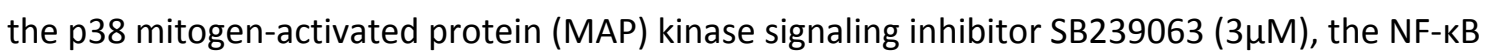
inhibitor BAY-117082 $(1 \mu \mathrm{M})$ or the c-Jun N-terminal kinase (JNK) inhibitor SP600125 $(10 \mu \mathrm{M})$ for 60 minutes before challenge with $A A(100 \mu M)$ in combination with the viral mimic Polyl:C $(A, B)$, Polyl:C alone $(C, D)$ or $A A(100 \mu M)$ in combination with $L T A(10 \mu \mathrm{g} / \mathrm{mL})(E, F)$. Cell free supernatants were collected after $24 \mathrm{~h}$ and IL-6 (A, C, E) and CXCL8 (B, D, F) release was measured using ELISA. All data are represented as $\%$ cytokine release \pm standard error of the mean. All treatments with inhibitor are compared to their respective control in the absence of the inhibitor using one-way ANOVA with a Bonferroni post-test. Significance is represented as $*(p<0.05)$ and ${ }^{* *}(p<0.01)$ or ${ }^{* * *}(p<0.001)$ or $* * * *(p<0.0001)$.

Figure 9. Greater cytokine release with combined arachidonic acid and human rhinovirus 16 challenge, than either alone in human pulmonary fibroblasts and BEAS-2Bs. Human primary pulmonary fibroblasts $(n=9)$ (patients) (A, B) or BEAS-2Bs $(n=7)$ (replicates) (C, D) were unstimulated (control) or challenged with arachidonic acid (AA) in 0.1\% BSA-DMEM $(100 \mu \mathrm{M})$ for $4 \mathrm{~h}$ prior to infection with human rhinovirus serotype-16 (RV16) at a multiplicity of infection (MOI) of 1 for another 24h. Cell free supernatants were collected and IL-6 (A, C) and CXCL8 (B, D) release was measured using ELISA. All data are represented as mean \pm standard error of the mean. All challenges $\mathrm{RV} 16$ are compared to their respective challenge without RV16 and RV16 alone, using a one-way ANOVA with a Bonferroni post-test. Significance is represented as $*(p<0.05), * *(p<0.01)$ or $* * *$ $(p<0.001)$. 


\section{References}

1. Ng M, Fleming T, Robinson M, Thomson B, Graetz N, Margono C, Mullany EC, Biryukov S, Abbafati $C$, Abera SF, et al. Global, regional, and national prevalence of overweight and obesity in children and adults during 1980-2013: A systematic analysis for the global burden of disease study 2013. Lancet (London, England) 2014;384(9945):766-781.

2. Gruchala-Niedoszytko M, Malgorzewicz S, Niedoszytko M, Gnacinska M, Jassem E. The influence of obesity on inflammation and clinical symptoms in asthma. Advances in medical sciences 2013;58(1):15-21.

3. Mosen DM, Schatz M, Magid DJ, Camargo CA, Jr. The relationship between obesity and asthma severity and control in adults. The Journal of allergy and clinical immunology 2008;122(3):507-511.e506.

4. Telenga ED, Tideman SW, Kerstjens HA, Hacken NH, Timens W, Postma DS, van den Berge M. Obesity in asthma: More neutrophilic inflammation as a possible explanation for a reduced treatment response. Allergy 2012;67(8):1060-1068.

5. Scott HA, Gibson PG, Garg ML, Wood LG. Airway inflammation is augmented by obesity and fatty acids in asthma. The European respiratory journal 2011;38(3):594-602.

6. Schatz M, Zeiger RS, Zhang F, Chen W, Yang SJ, Camargo CA, Jr. Overweight/obesity and risk of seasonal asthma exacerbations. The journal of allergy and clinical immunology In practice 2013;1(6):618-622.

7. Rodrigo GJ, Plaza V. Body mass index and response to emergency department treatment in adults with severe asthma exacerbations: A prospective cohort study. Chest 2007;132(5):1513-1519. 8. Wark PA, Gibson PG. Asthma exacerbations . 3: Pathogenesis. Thorax 2006;61(10):909-915.

9. Yamaya M. Virus infection-induced bronchial asthma exacerbation. Pulmonary medicine 2012;2012:834826.

10. Kim CK, Callaway Z, Gern JE. Viral infections and associated factors that promote acute exacerbations of asthma. Allergy, asthma \& immunology research 2018;10(1):12-17.

11. Henderson FW, Clyde WA, Jr., Collier AM, Denny FW, Senior RJ, Sheaffer Cl, Conley WG, 3rd, Christian RM. The etiologic and epidemiologic spectrum of bronchiolitis in pediatric practice. The Journal of pediatrics 1979;95(2):183-190.

12. Nisar N, Guleria R, Kumar S, Chand Chawla T, Ranjan Biswas N. Mycoplasma pneumoniae and its role in asthma. Postgraduate medical journal 2007;83(976):100-104.

13. Dhurandhar NV, Bailey D, Thomas D. Interaction of obesity and infections. Obesity reviews : an official journal of the International Association for the Study of Obesity 2015;16(12):1017-1029.

14. Campitelli MA, Rosella LC, Kwong JC. The association between obesity and outpatient visits for acute respiratory infections in ontario, canada. International journal of obesity (2005) 2014;38(1):113-119.

15. Louie JK, Acosta M, Samuel MC, Schechter R, Vugia DJ, Harriman K, Matyas BT. A novel risk factor for a novel virus: Obesity and 2009 pandemic influenza a (h1n1). Clinical infectious diseases : an official publication of the Infectious Diseases Society of America 2011;52(3):301-312.

16. Morgan OW, Bramley A, Fowlkes A, Freedman DS, Taylor TH, Gargiullo P, Belay B, Jain S, Cox C, Kamimoto L, et al. Morbid obesity as a risk factor for hospitalization and death due to 2009 pandemic influenza a(h1n1) disease. PloS one 2010;5(3):e9694.

17. Wood LG. Diet, obesity, and asthma. Annals of the American Thoracic Society 2017;14(Supplement_5):S332-s338.

18. van Oostrom AJ, Sijmonsma TP, Verseyden C, Jansen EH, de Koning EJ, Rabelink TJ, Castro Cabezas M. Postprandial recruitment of neutrophils may contribute to endothelial dysfunction. Journal of lipid research 2003;44(3):576-583.

19. Wood LG, Garg ML, Gibson PG. A high-fat challenge increases airway inflammation and impairs bronchodilator recovery in asthma. The Journal of allergy and clinical immunology 2011;127(5):1133-1140. 
20. Boden G. Obesity and free fatty acids. Endocrinology and metabolism clinics of North America 2008;37(3):635-646, viii-ix.

21. Abdelmagid SA, Clarke SE, Nielsen DE, Badawi A, El-Sohemy A, Mutch DM, Ma DW. Comprehensive profiling of plasma fatty acid concentrations in young healthy canadian adults. PloS one 2015;10(2):e0116195.

22. Feng R, Luo C, Li C, Du S, Okekunle AP, Li Y, Chen Y, Zi T, Niu Y. Free fatty acids profile among lean, overweight and obese non-alcoholic fatty liver disease patients: A case - control study. Lipids in health and disease 2017;16(1):165.

23. Guerendiain M, Montes R, Lopez-Belmonte G, Martin-Matillas M, Castellote Al, MartinBautista E, Marti A, Martinez JA, Moreno L, Garagorri JM, et al. Changes in plasma fatty acid composition are associated with improvements in obesity and related metabolic disorders: A therapeutic approach to overweight adolescents. Clinical nutrition (Edinburgh, Scotland) 2018;37(1):149-156.

24. Huang S, Rutkowsky JM, Snodgrass RG, Ono-Moore KD, Schneider DA, Newman JW, Adams $\mathrm{SH}$, Hwang DH. Saturated fatty acids activate tIr-mediated proinflammatory signaling pathways. Journal of lipid research 2012;53(9):2002-2013.

25. Calder PC. Polyunsaturated fatty acids and inflammatory processes: New twists in an old tale. Biochimie 2009;91(6):791-795.

26. Papadopoulos NG, Bates PJ, Bardin PG, Papi A, Leir SH, Fraenkel DJ, Meyer J, Lackie PM, Sanderson G, Holgate ST, et al. Rhinoviruses infect the lower airways. The Journal of infectious diseases 2000;181(6):1875-1884.

27. Krimmer D, Ichimaru Y, Burgess J, Black J, Oliver B. Exposure to biomass smoke extract enhances fibronectin release from fibroblasts. PloS one 2013;8(12):e83938.

28. Gupta S, Knight AG, Gupta S, Keller JN, Bruce-Keller AJ. Saturated long-chain fatty acids activate inflammatory signaling in astrocytes. Journal of neurochemistry 2012;120(6):1060-1071.

29. Kuo C, Lim S, King NJ, Bartlett NW, Walton RP, Zhu J, Glanville N, Aniscenko J, Johnston SL, Burgess JK, et al. Rhinovirus infection induces expression of airway remodelling factors in vitro and in vivo. Respirology (Carlton, Vic) 2011;16(2):367-377.

30. Bartlett NW, Walton RP, Edwards MR, Aniscenko J, Caramori G, Zhu J, Glanville N, Choy KJ, Jourdan $\mathrm{P}$, Burnet J, et al. Mouse models of rhinovirus-induced disease and exacerbation of allergic airway inflammation. Nature medicine 2008;14(2):199-204.

31. Simopoulos AP. The importance of the ratio of omega-6/omega-3 essential fatty acids. Biomedicine \& pharmacotherapy = Biomedecine \& pharmacotherapie 2002;56(8):365-379.

32. Huang G, Shi LZ, Chi H. Regulation of jnk and p38 mapk in the immune system: Signal integration, propagation and termination. Cytokine 2009;48(3):161-169.

33. Guven-Maiorov E, Keskin O, Gursoy A, VanWaes C, Chen Z, Tsai CJ, Nussinov R. The architecture of the tir domain signalosome in the toll-like receptor-4 signaling pathway. Scientific reports 2015;5:13128.

34. Calder PC. Omega-3 polyunsaturated fatty acids and inflammatory processes: Nutrition or pharmacology? British journal of clinical pharmacology 2013;75(3):645-662.

35. Sanders SP, Kim J, Connolly KR, Porter JD, Siekierski ES, Proud D. Nitric oxide inhibits rhinovirus-induced granulocyte macrophage colony-stimulating factor production in bronchial epithelial cells. American journal of respiratory cell and molecular biology 2001;24(3):317-325. 36. Becher B, Tugues S, Greter M. Gm-csf: From growth factor to central mediator of tissue inflammation. Immunity 2016;45(5):963-973.

37. Marques RE, Guabiraba R, Russo RC, Teixeira MM. Targeting ccl5 in inflammation. Expert opinion on therapeutic targets 2013;17(12):1439-1460.

38. Koya T, Takeda K, Kodama T, Miyahara N, Matsubara S, Balhorn A, Joetham A, Dakhama A, Gelfand EW. Rantes ( $\mathrm{ccl} 5$ ) regulates airway responsiveness after repeated allergen challenge.

American journal of respiratory cell and molecular biology 2006;35(2):147-154. 
39. Kurai D, Saraya T, Ishii H, Takizawa H. Virus-induced exacerbations in asthma and copd. Frontiers in microbiology 2013;4:293.

40. Wos M, Sanak M, Soja J, Olechnowicz H, Busse WW, Szczeklik A. The presence of rhinovirus in lower airways of patients with bronchial asthma. American journal of respiratory and critical care medicine 2008;177(10):1082-1089.

41. Van Ly D, King NJ, Moir LM, Burgess JK, Black JL, Oliver BG. Effects of beta(2) agonists, corticosteroids, and novel therapies on rhinovirus-induced cytokine release and rhinovirus replication in primary airway fibroblasts. Journal of allergy 2011;2011:457169.

42. Ghildyal R, Dagher H, Donninger H, de Silva D, Li X, Freezer NJ, Wilson JW, Bardin PG. Rhinovirus infects primary human airway fibroblasts and induces a neutrophil chemokine and a permeability factor. Journal of medical virology 2005;75(4):608-615.

43. Muralidharan S, Mandrekar P. Cellular stress response and innate immune signaling: Integrating pathways in host defense and inflammation. Journal of leukocyte biology 2013;94(6):1167-1184.

44. Zhou Y, Guo M, Wang X, Li J, Wang Y, Ye L, Dai M, Zhou L, Persidsky Y, Ho W. TIr3 activation efficiency by high or low molecular mass poly i:C. Innate immunity 2013;19(2):184-192.

45. Cunningham AF, Johnston SL, Julious SA, Lampe FC, Ward ME. Chronic chlamydia pneumoniae infection and asthma exacerbations in children. The European respiratory journal 1998;11(2):345-349.

46. Seo HS, Michalek SM, Nahm MH. Lipoteichoic acid is important in innate immune responses to gram-positive bacteria. Infection and immunity 2008;76(1):206-213.

47. Mayer AK, Muehmer M, Mages J, Gueinzius K, Hess C, Heeg K, Bals R, Lang R, Dalpke AH. Differential recognition of tlr-dependent microbial ligands in human bronchial epithelial cells. Journal of immunology (Baltimore, Md : 1950) 2007;178(5):3134-3142.

48. Armstrong L, Medford AR, Uppington KM, Robertson J, Witherden IR, Tetley TD, Millar AB. Expression of functional toll-like receptor- 2 and -4 on alveolar epithelial cells. American journal of respiratory cell and molecular biology 2004;31(2):241-245.

49. Ajuwon KM, Spurlock ME. Palmitate activates the nf-kappab transcription factor and induces il-6 and tnfalpha expression in 3t3-I1 adipocytes. The Journal of nutrition 2005;135(8):1841-1846.

50. Lee JY, Zhao L, Youn HS, Weatherill AR, Tapping R, Feng L, Lee WH, Fitzgerald KA, Hwang DH. Saturated fatty acid activates but polyunsaturated fatty acid inhibits toll-like receptor 2 dimerized with toll-like receptor 6 or 1. The Journal of biological chemistry 2004;279(17):16971-16979.

51. Patel C, Ghanim H, Ravishankar S, Sia CL, Viswanathan P, Mohanty P, Dandona P. Prolonged reactive oxygen species generation and nuclear factor-kappab activation after a high-fat, highcarbohydrate meal in the obese. The Journal of clinical endocrinology and metabolism 2007;92(11):4476-4479.

52. Ghanim H, Sia CL, Upadhyay M, Korzeniewski K, Viswanathan P, Abuaysheh S, Mohanty P, Dandona P. Orange juice neutralizes the proinflammatory effect of a high-fat, high-carbohydrate meal and prevents endotoxin increase and toll-like receptor expression. The American journal of clinical nutrition 2010;91(4):940-949.

53. Alt E, Yan Y, Gehmert S, Song YH, Altman A, Gehmert S, Vykoukal D, Bai X. Fibroblasts share mesenchymal phenotypes with stem cells, but lack their differentiation and colony-forming potential. Biology of the cell 2011;103(4):197-208.

54. Xing Z, Jordana M, Braciak T, Ohtoshi T, Gauldie J. Lipopolysaccharide induces expression of granulocyte/macrophage colony-stimulating factor, interleukin-8, and interleukin- 6 in human nasal, but not lung, fibroblasts: Evidence for heterogeneity within the respiratory tract. American journal of respiratory cell and molecular biology 1993;9(3):255-263.

55. Zhang RN, Pan Q, Zhang Z, Cao HX, Shen F, Fan JG. Saturated fatty acid inhibits viral replication in chronic hepatitis $b$ virus infection with nonalcoholic fatty liver disease by toll-like receptor 4-mediated innate immune response. Hepatitis monthly 2015;15(5):e27909. 
56. Svahn SL, Grahnemo L, Palsdottir V, Nookaew I, Wendt K, Gabrielsson B, Schele E, Benrick A, Andersson N, Nilsson S, et al. Dietary polyunsaturated fatty acids increase survival and decrease bacterial load during septic staphylococcus aureus infection and improve neutrophil function in mice. Infection and immunity 2015;83(2):514-521.

57. Kelley DS, Taylor PC, Nelson GJ, Mackey BE. Arachidonic acid supplementation enhances synthesis of eicosanoids without suppressing immune functions in young healthy men. Lipids 1998;33(2):125-130.

58. Jordao L, Lengeling A, Bordat Y, Boudou F, Gicquel B, Neyrolles O, Becker PD, Guzman CA, Griffiths $\mathrm{G}$, Anes $\mathrm{E}$. Effects of omega-3 and -6 fatty acids on mycobacterium tuberculosis in macrophages and in mice. Microbes and infection 2008;10(12-13):1379-1386.

59. Underwood DC, Osborn RR, Kotzer CJ, Adams JL, Lee JC, Webb EF, Carpenter DC, Bochnowicz S, Thomas HC, Hay DW, et al. Sb 239063, a potent p38 map kinase inhibitor, reduces inflammatory cytokine production, airways eosinophil infiltration, and persistence. The Journal of pharmacology and experimental therapeutics 2000;293(1):281-288.

60. Ammit AJ, Lazaar AL, Irani C, O'Neill GM, Gordon ND, Amrani Y, Penn RB, Panettieri RA, Jr. Tumor necrosis factor-alpha-induced secretion of rantes and interleukin- 6 from human airway smooth muscle cells: Modulation by glucocorticoids and beta-agonists. American journal of respiratory cell and molecular biology 2002;26(4):465-474.

61. Terry CF, Loukaci V, Green FR. Cooperative influence of genetic polymorphisms on interleukin 6 transcriptional regulation. The Journal of biological chemistry 2000;275(24):1813818144.

62. Bonanno A, Albano GD, Siena L, Montalbano AM, Riccobono L, Anzalone G, Chiappara G, Gagliardo R, Profita M, Sala A. Prostaglandin e(2) possesses different potencies in inducing vascular endothelial growth factor and interleukin-8 production in copd human lung fibroblasts.

Prostaglandins, leukotrienes, and essential fatty acids 2016;106:11-18.

63. Tavakoli S, Cowan MJ, Benfield T, Logun C, Shelhamer JH. Prostaglandin e(2)-induced interleukin- 6 release by a human airway epithelial cell line. American journal of physiology Lung cellular and molecular physiology 2001;280(1):L127-133.

64. Ricciotti E, FitzGerald GA. Prostaglandins and inflammation. Arteriosclerosis, thrombosis, and vascular biology 2011;31(5):986-1000. 


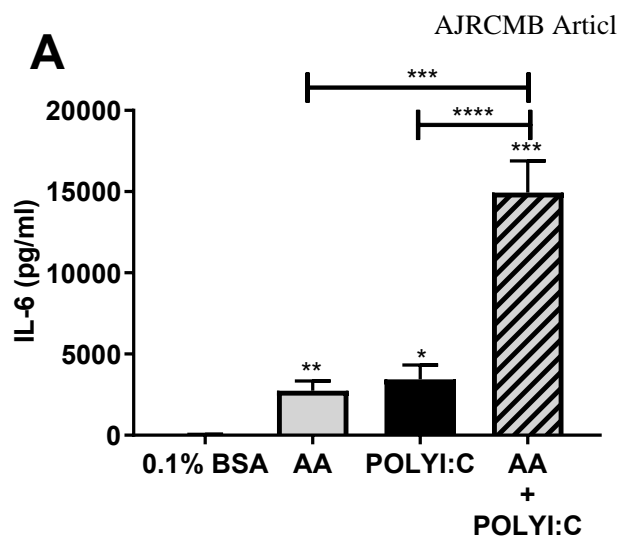

D

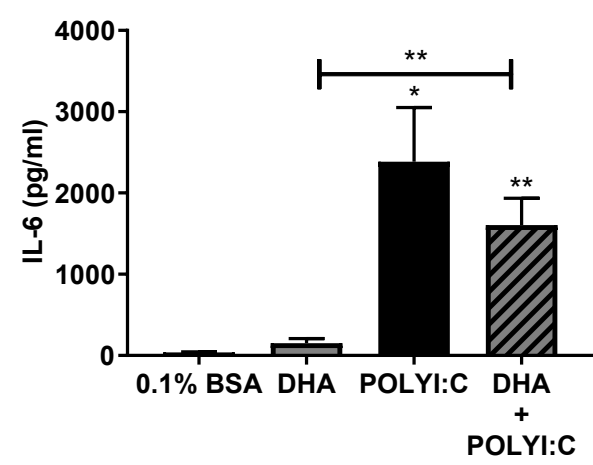

G

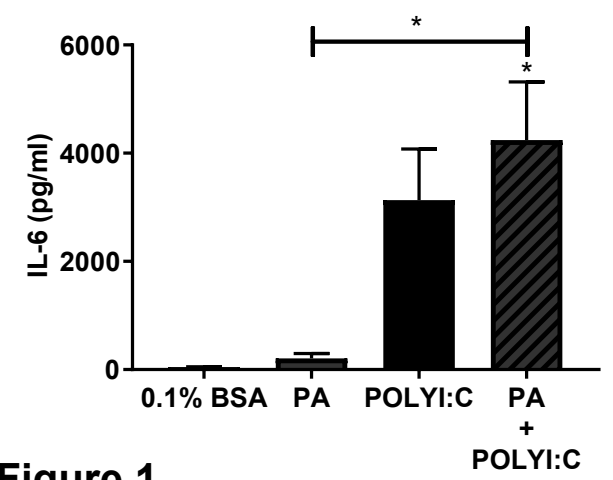

E

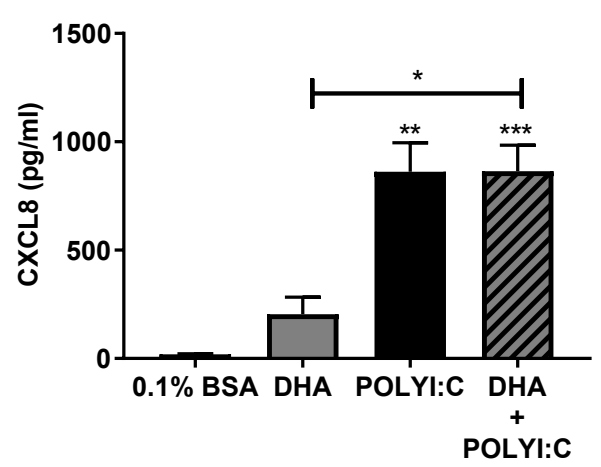

\section{H}

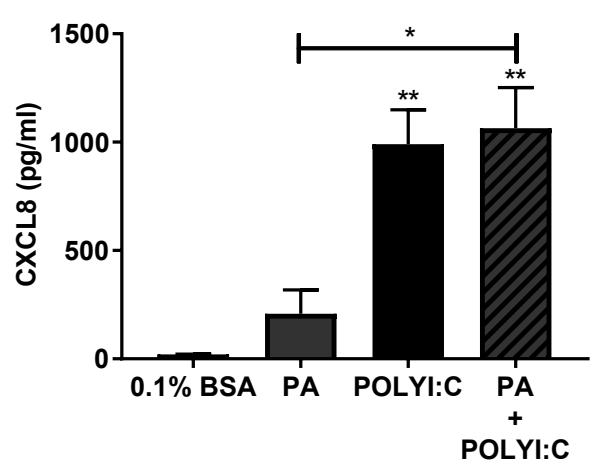

Copyright $@ 2019$ by the American Thoracic Society
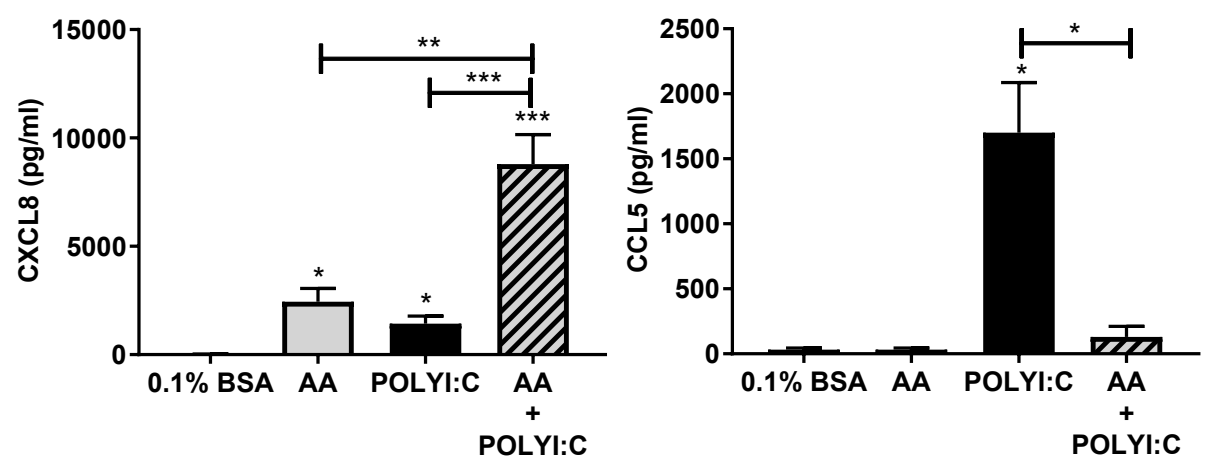

$\mathbf{F}$
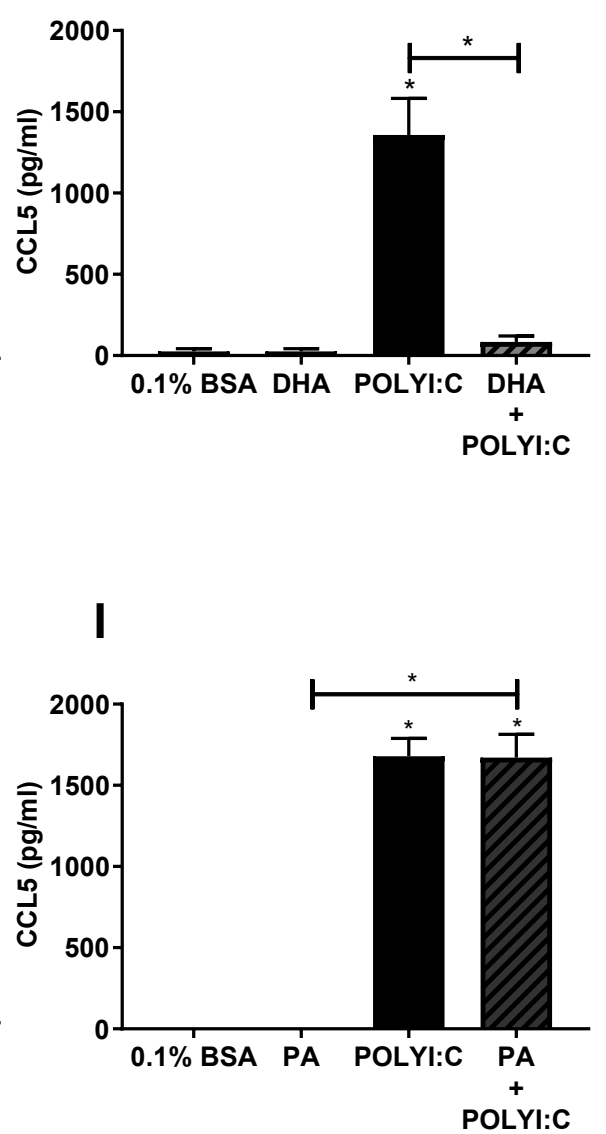

Figure 1 
Page 31 of 43
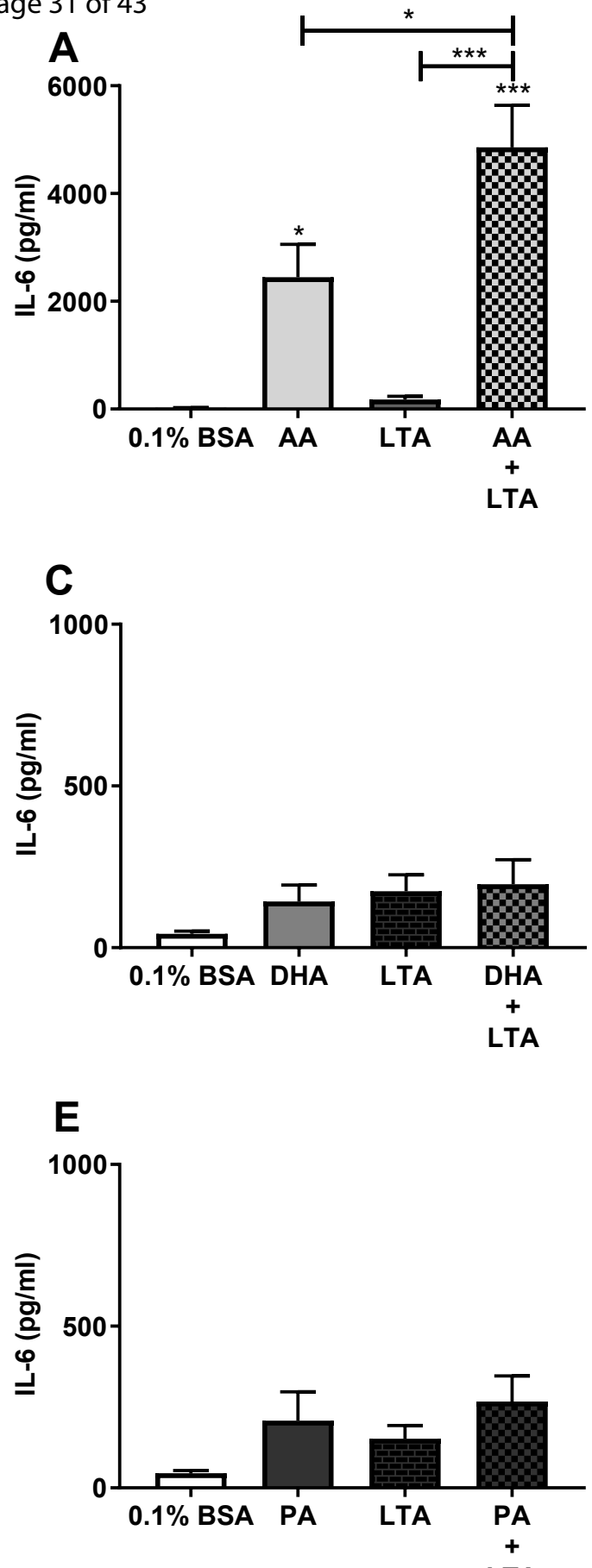

Figure 2
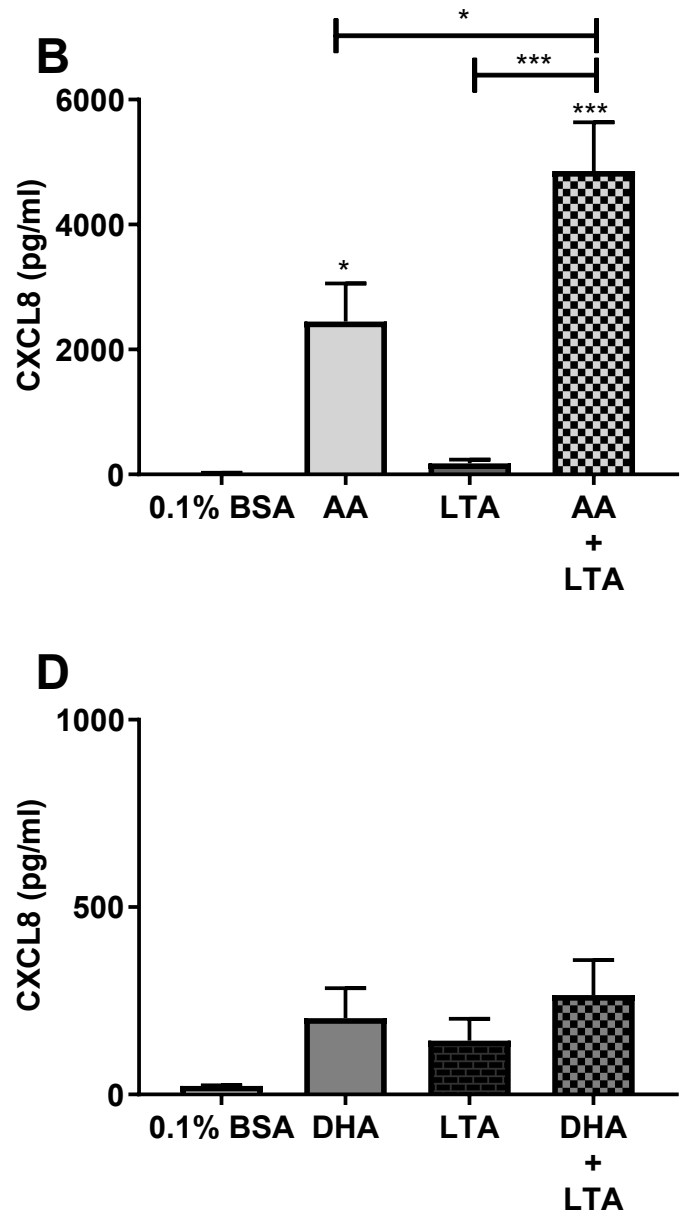

$\mathbf{F}$

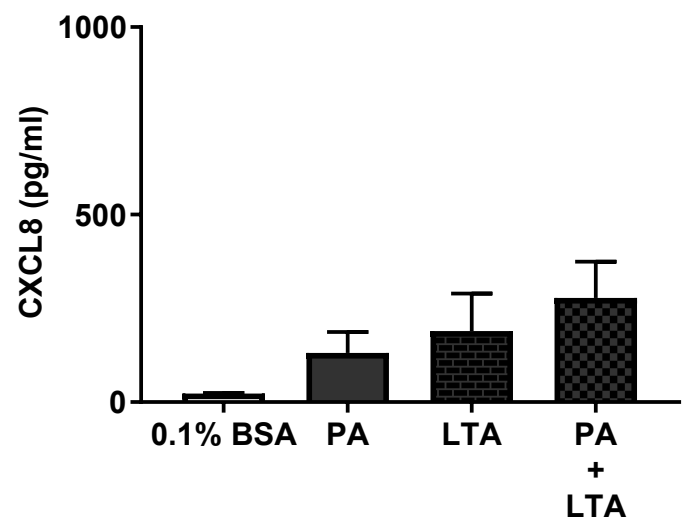

Copyright ( $\odot 2019$ by the American Thoracic Society 
A

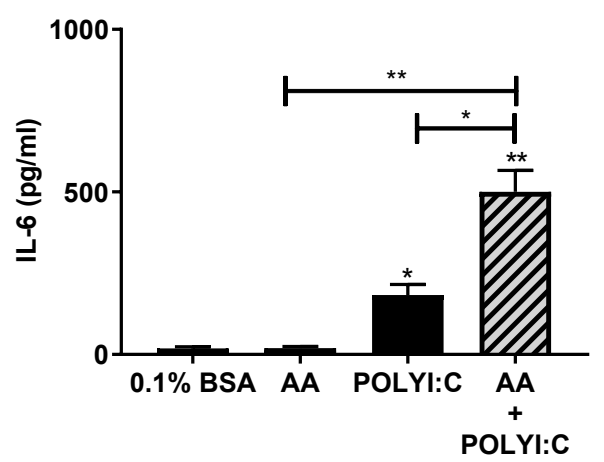

D

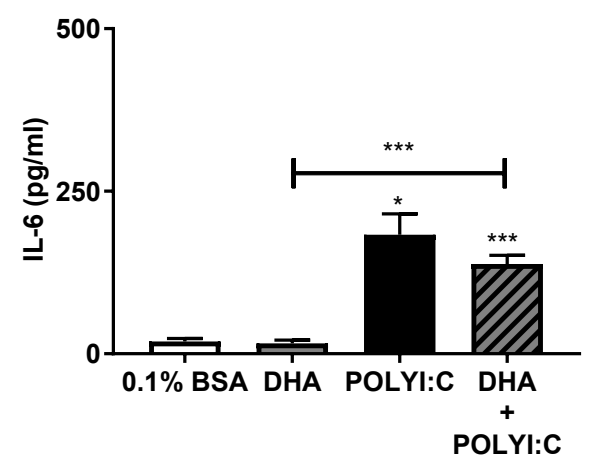

G

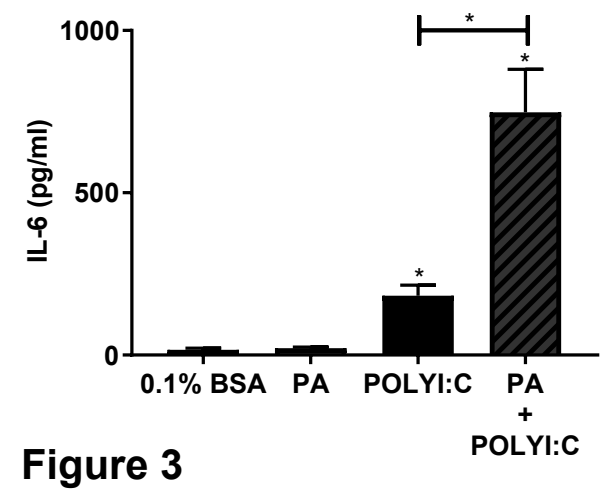

B

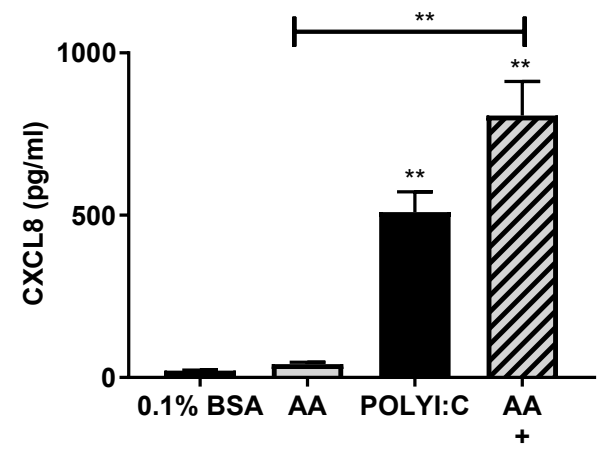

E

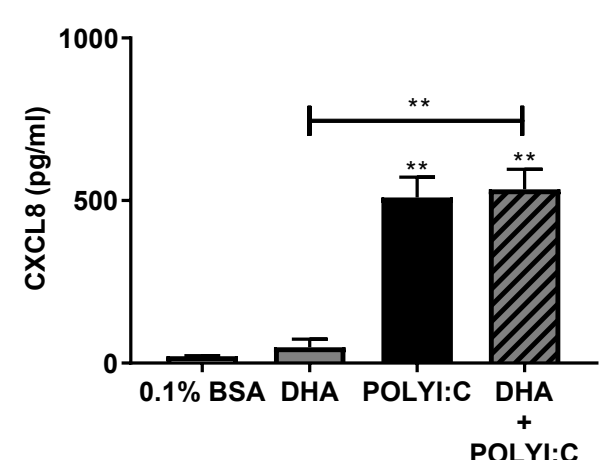

H

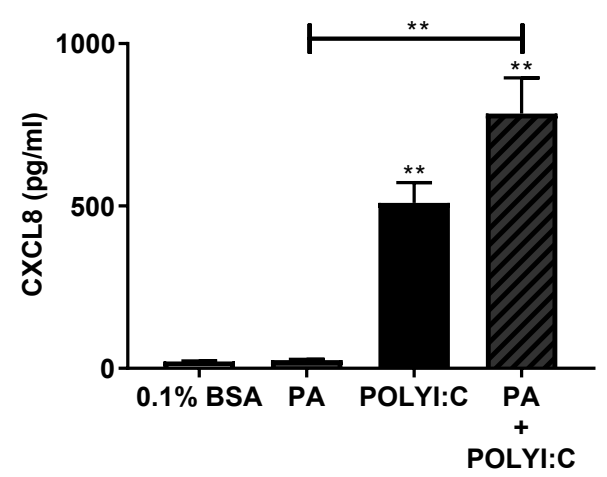

Copyright $\odot 2019$ by the American Thoracic Society
C

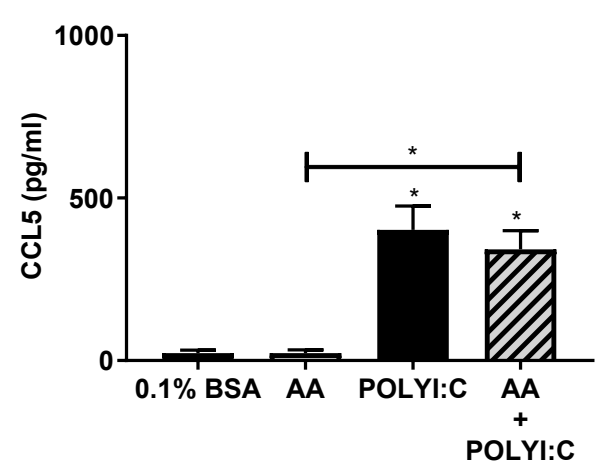

$\mathbf{F}$
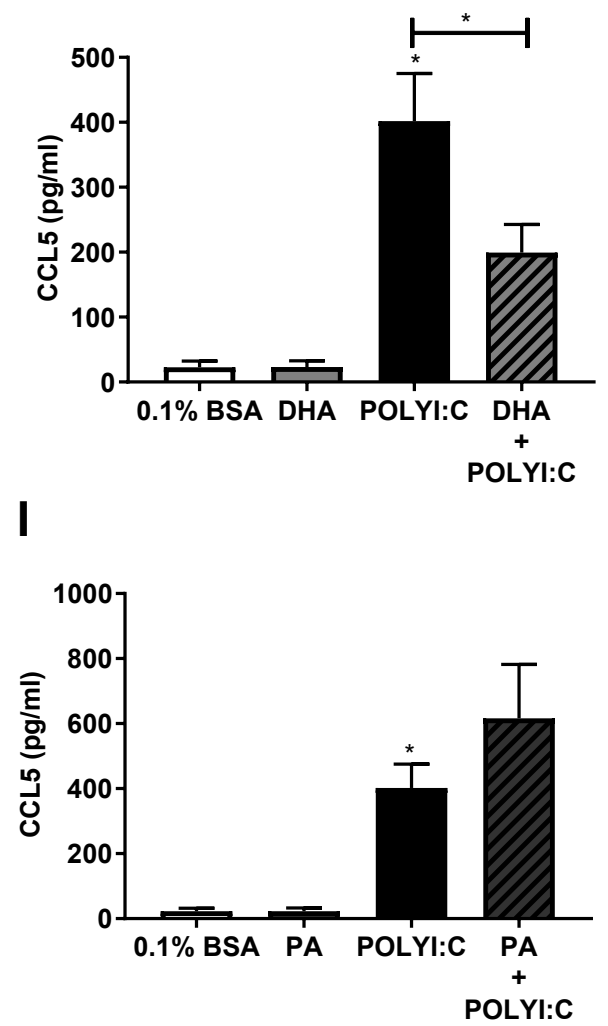

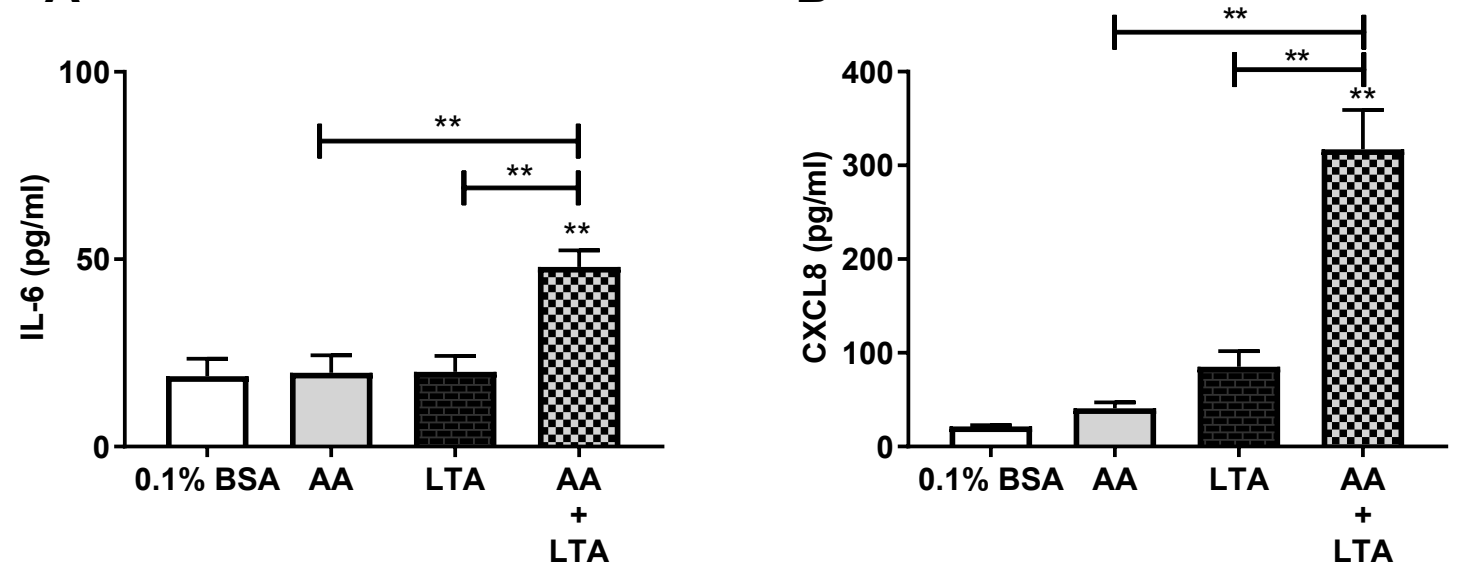

C
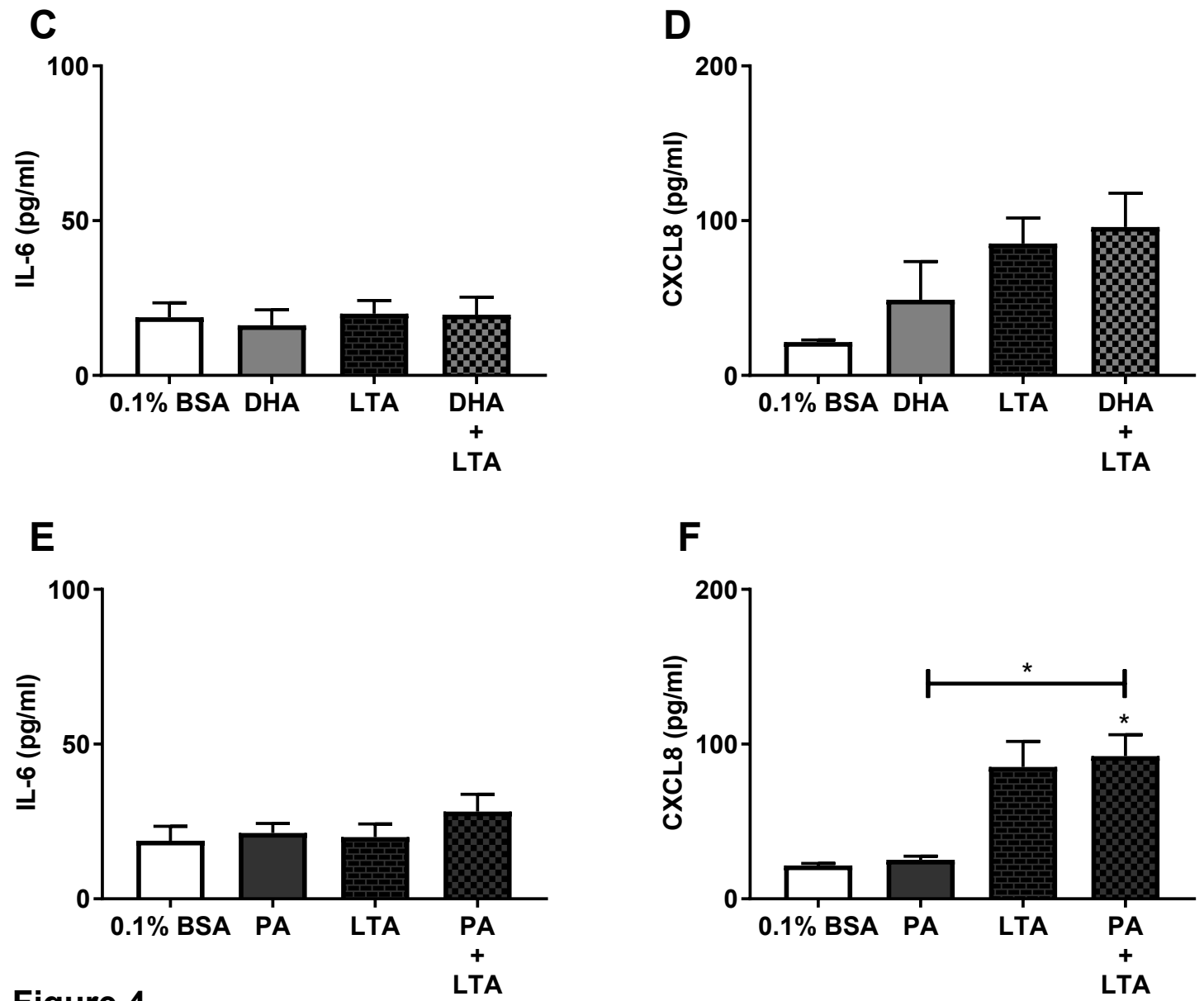

Copyright $@ 2019$ by the American Thoracic Society 

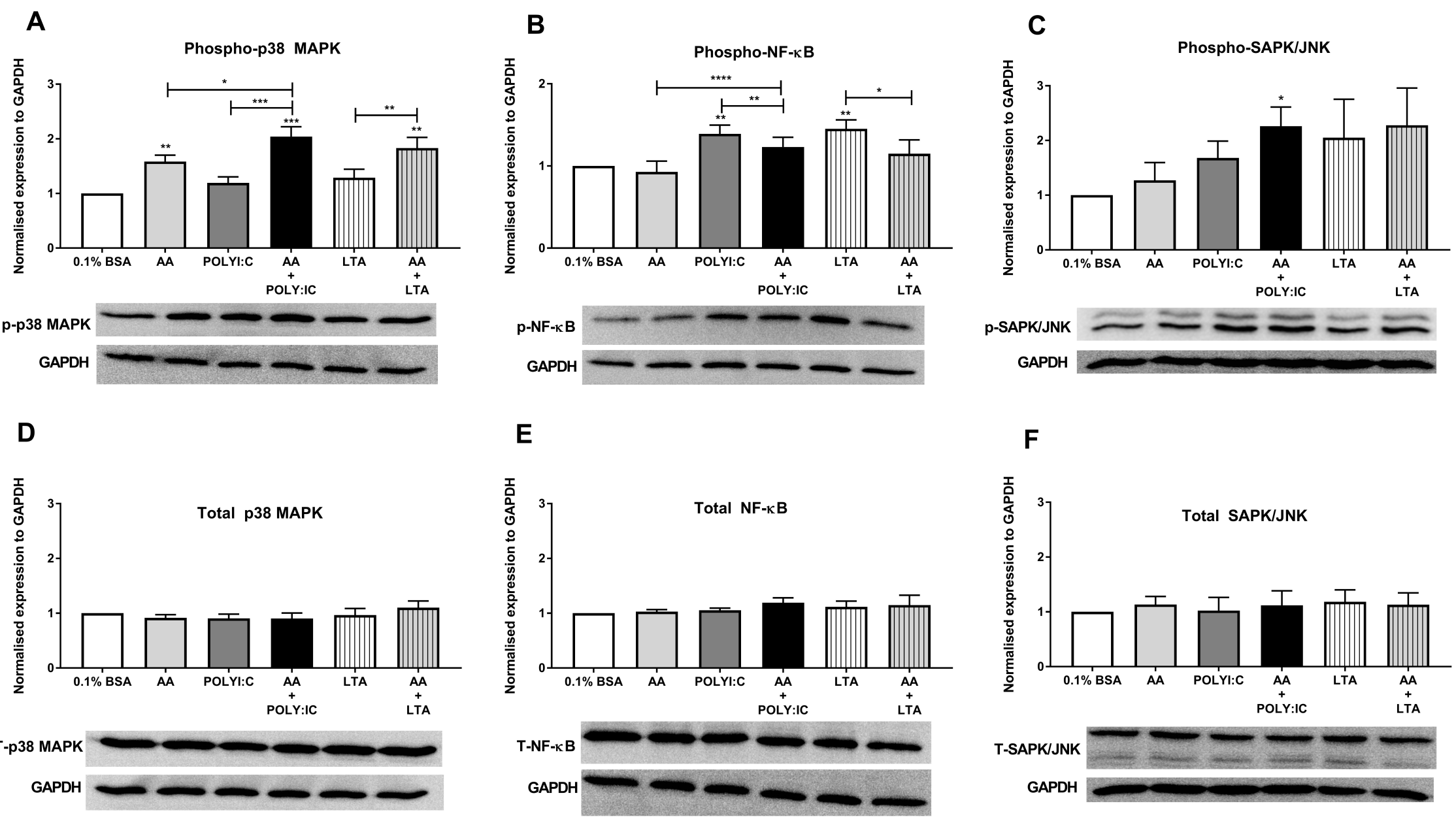

Figure 5 

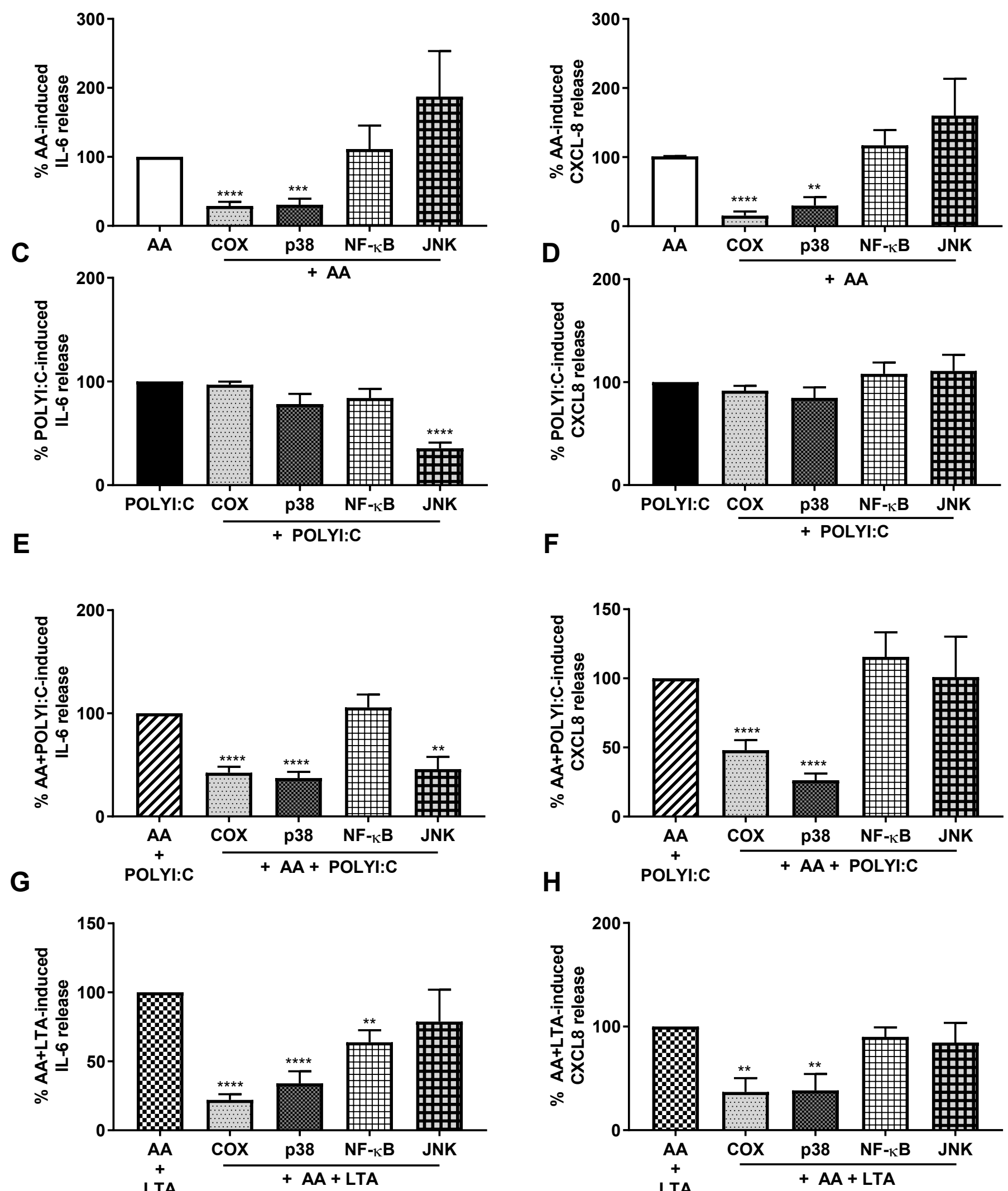

Figure 6

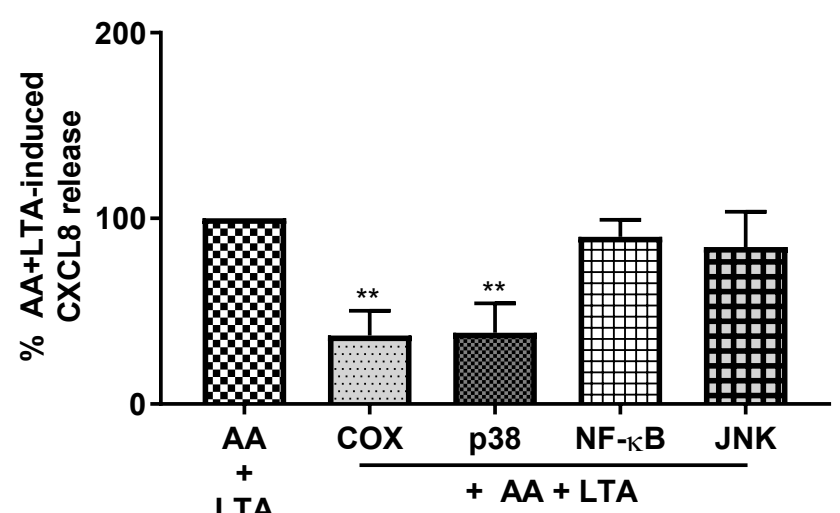


A AJRCMB Articles in Press. Published on 16-January-2019 as 10.1165/rcmb.2018-02150C
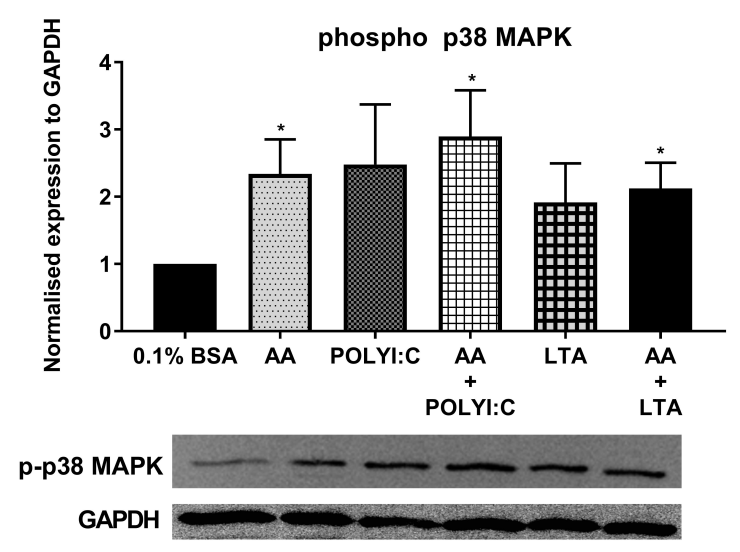

\section{D}

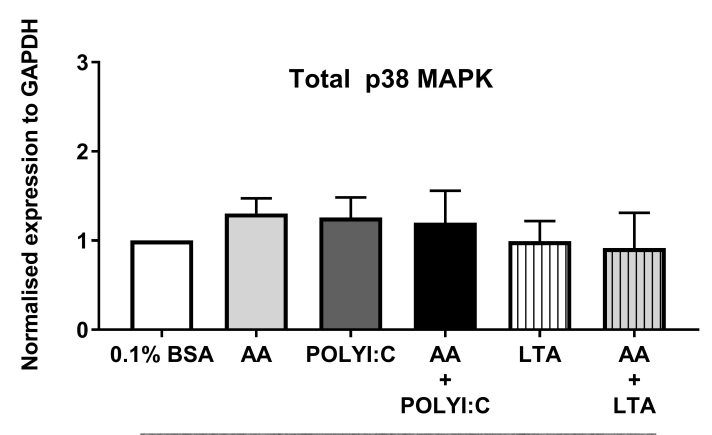

T-p38 MAPK $-\infty$

GAPDH $-\longrightarrow-\cdots$
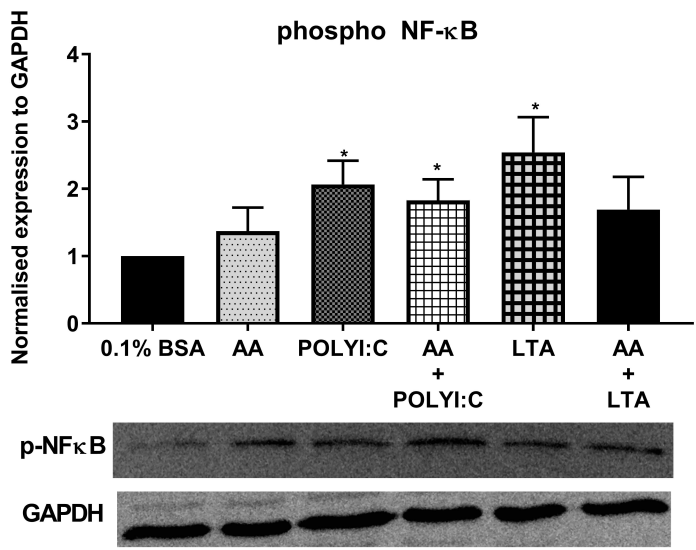

E

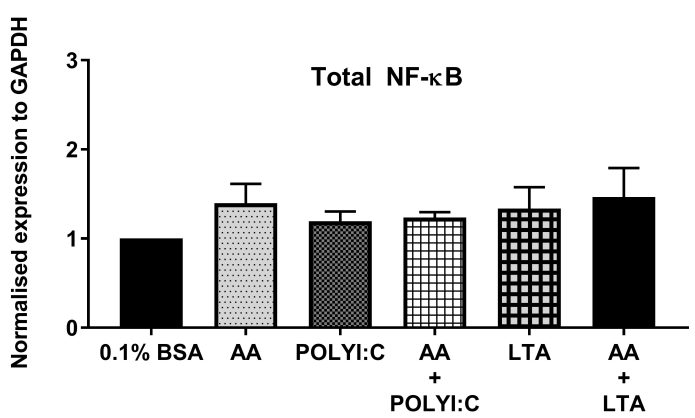

T-NF-KB

GAPDH

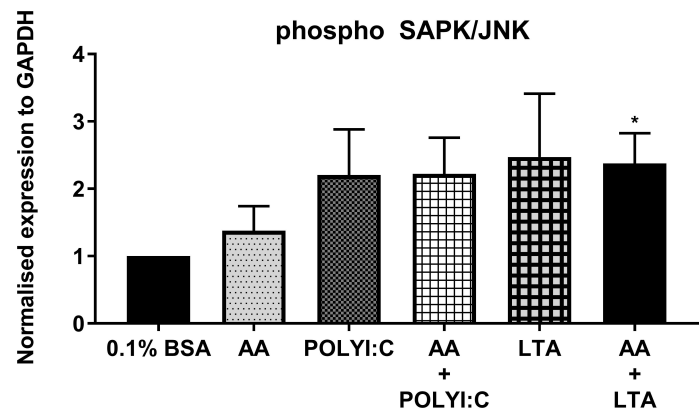

p-SAPKIJNK

GAPDH

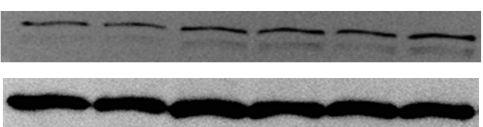

$\mathbf{F}$

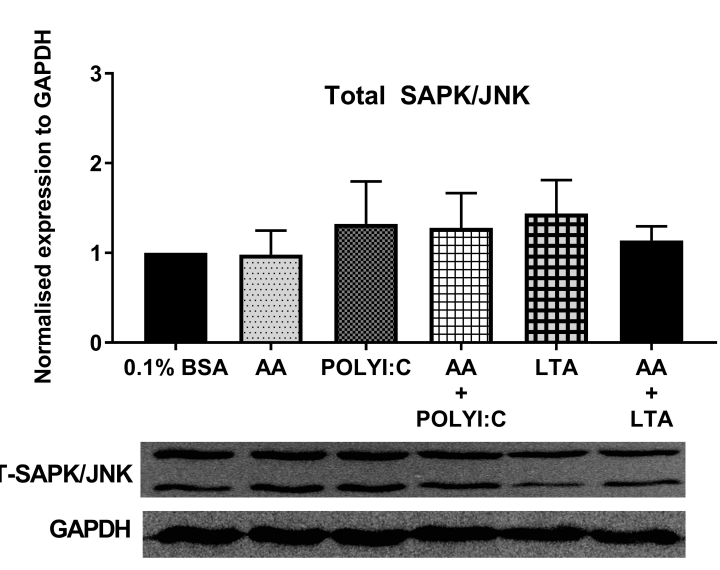

Figure 7 

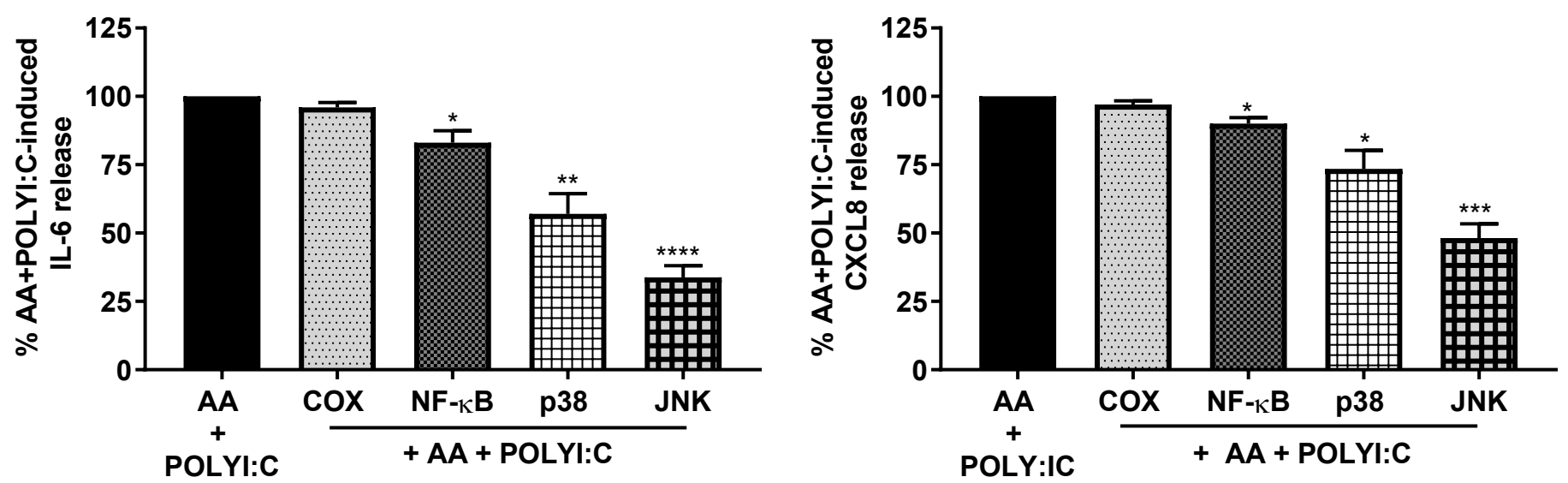

C
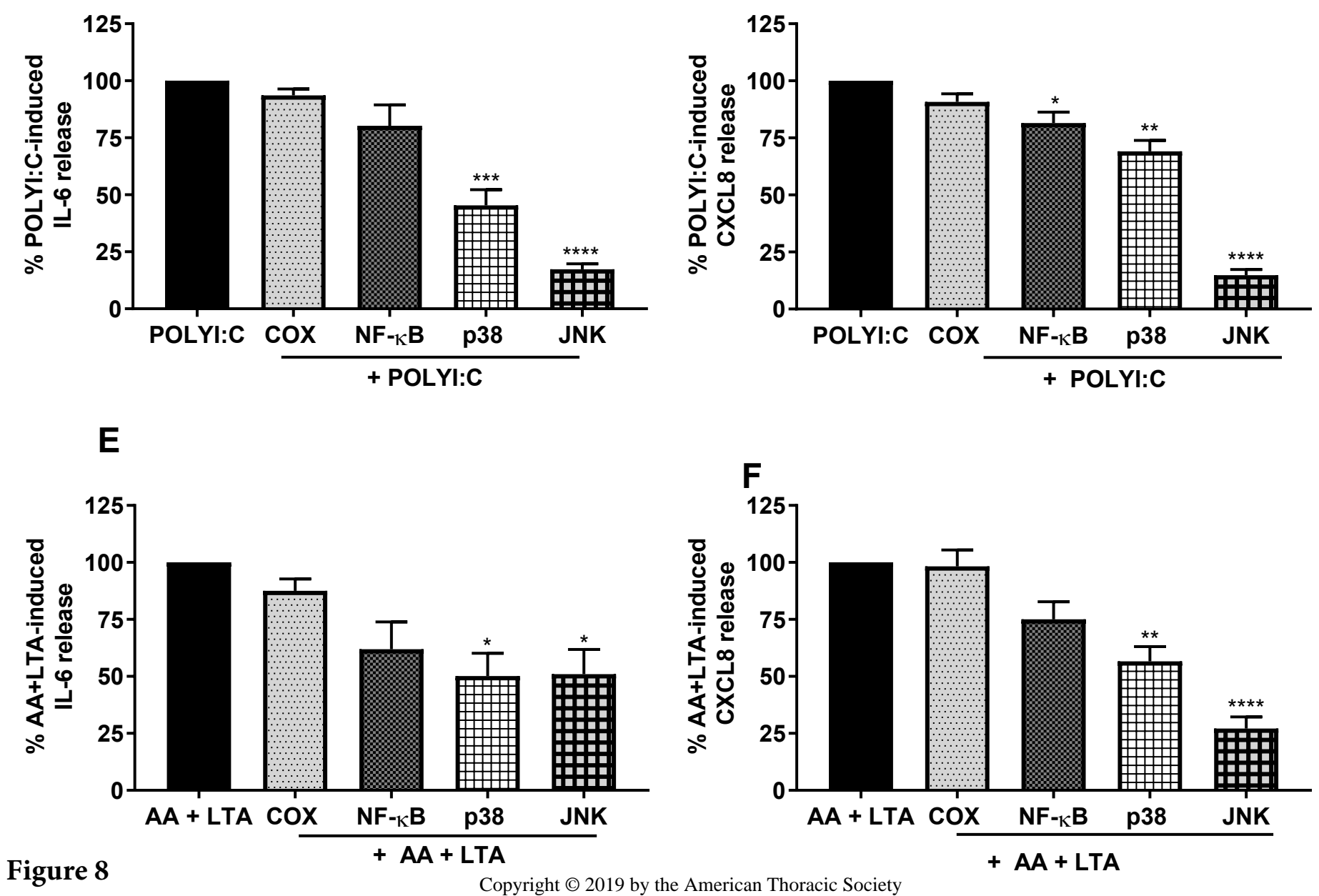


\section{ONLINE SUPPLEMENT}

\section{Dietary fatty acids amplify inflammatory responses to infection through p38 MAP} kinase signaling

Sandra Rutting, Razia Zakarya, Jack Bozier, Dia Xenaki, Jay C. Horvat, Lisa G. Wood, Philip M. Hansbro, Brian G. Oliver 


\section{Supplementary Methods}

\section{Cell culture HPFs and BEAS-2Bs}

HPFs were seeded in 12 -well plates at a density of $6.2 \times 10^{4}$ cells $/ \mathrm{mL}$ in DMEM containing $5 \%$ fetal bovine serum (FBS) and 1\% Antibiotic-Antimycotic (Gibco, Grand Island, New York, US) and grown to sub confluence (3 days). The human bronchial epithelial cell line BEAS-2B was maintained in 10\% FBS and $1 \%$ Antibiotic-Antimycotic in DMEM. BEAS-2Bs were seeded at a density of $1 \times 10^{5} \mathrm{cells} / \mathrm{mL}$ in $12-$ well plates and grown for 24 hours. Both cell types were quiesced for 24 hours prior to stimulation, by incubation in DMEM supplemented with $0.1 \%$ bovine serum albumin (BSA) (Sigma Aldrich, Castle Hill, NSW, Australia) and 1\% Antibiotic-Antimycotic. All experiments were carried out using fibroblasts between passage 2 and 6 .

\section{Western blotting}

To investigate the cell signalling pathways activated after challenge with the combinations of $A A$ and POLYI:C or LTA, relative levels of phosphorylated p38 mitogen-activated protein (MAP) kinase, NF-KB and stress-activated protein kinase/c-Jun NH2-terminal kinase (SAPK/JNK) from cell lysates were assessed by western blotting. Cells cultured in the presence or absence of $A A(100 \mu \mathrm{M})$ with or without POLYI:C $(10 \mu \mathrm{g} / \mathrm{ml})$ or LTA $(10 \mu \mathrm{g} / \mathrm{ml})$ for 30 min were lysed $(20 \mathrm{mM}$ Tris, $\mathrm{pH} 7.4,150 \mathrm{mM} \mathrm{NaCl}$, $1 \mathrm{mM} \mathrm{Na}_{2}$ EDTA, $1 \mathrm{mM}$ EGTA, 20mM NA $\mathrm{P}_{2} \mathrm{P}_{7}, 2 \mathrm{mM} \mathrm{Na}_{3} \mathrm{VO}_{4}, 1 \%$ Triton X- 100, $10 \%$ glycerol, $0.1 \%$ SDS, $0.5 \%$ sodium deoxycholate, $1 \%$ protease inhibitor cocktail set III (Millipore, USA) and $1 \mathrm{mM}$ phenylmethylsulfonyl fluoride (PMSF) (Amresco, Solon, OH, USA)). Cell lysates were separated by SDS/polyacrylamide gel electrophoresis (SDS-PAGE) on $10 \%$ gels and transferred to polyvinylidene difluoride (PVDF) membranes using a Trans-Blot Turbo transfer system (Bio-Rad). The membranes were incubated with rabbit anti-phospho p38 MAP kinase, rabbit anti-p38 MAP kinase, rabbit antiphospho NF-KB p65, rabbit anti-NF-KB p65, rabbit anti-phospho SAPK/JNK, rabbit anti-SAPK/JNK (1:1000, Cell Signaling Technology) or mouse anti-glyceraldehyde-3-phosphate dehydrogenase 
(GAPDH) (1:5000, Merck Millipore, USA) overnight at $4^{\circ} \mathrm{C}$. After washing with Tris-buffered salinecontaining Tween $20(0.05 \%)$, bound antibody was visualized using horseradish peroxidaseconjugated goat anti-rabbit IgG or horseradish peroxidase-conjugated anti-mouse IgG antibody (Dako, USA) and enhanced chemiluminescence, and imaged (Image Station 4000MM; Kodak Digital Science, New Haven, CT). GAPDH served as the control. 


\section{Supplementary Figure 1}

A
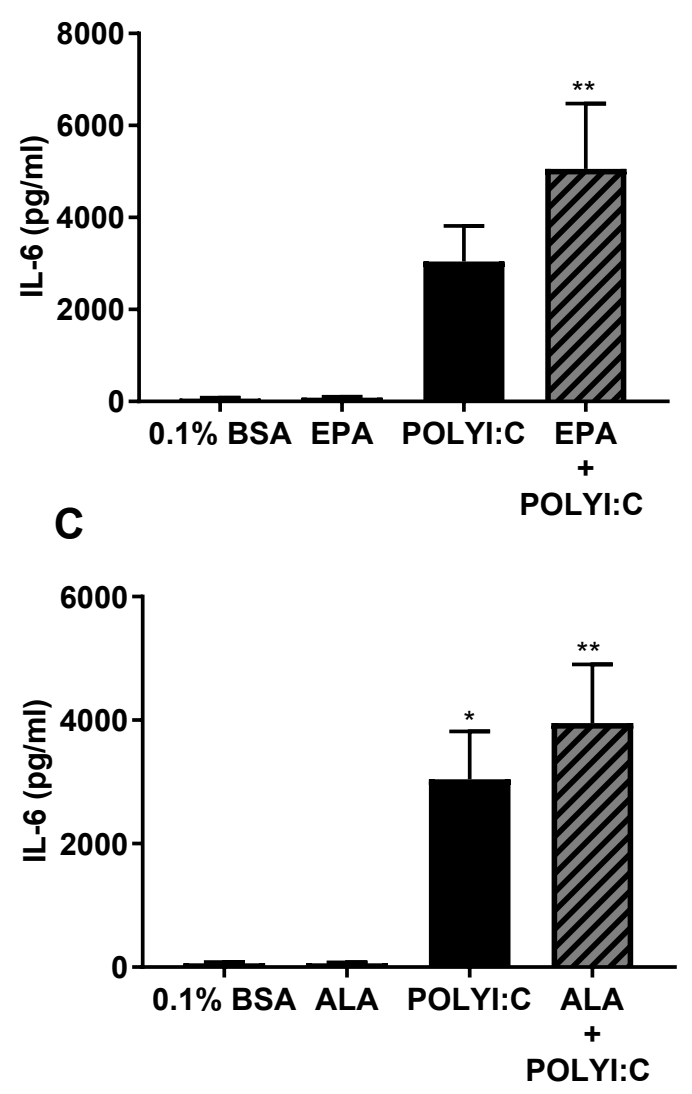

B
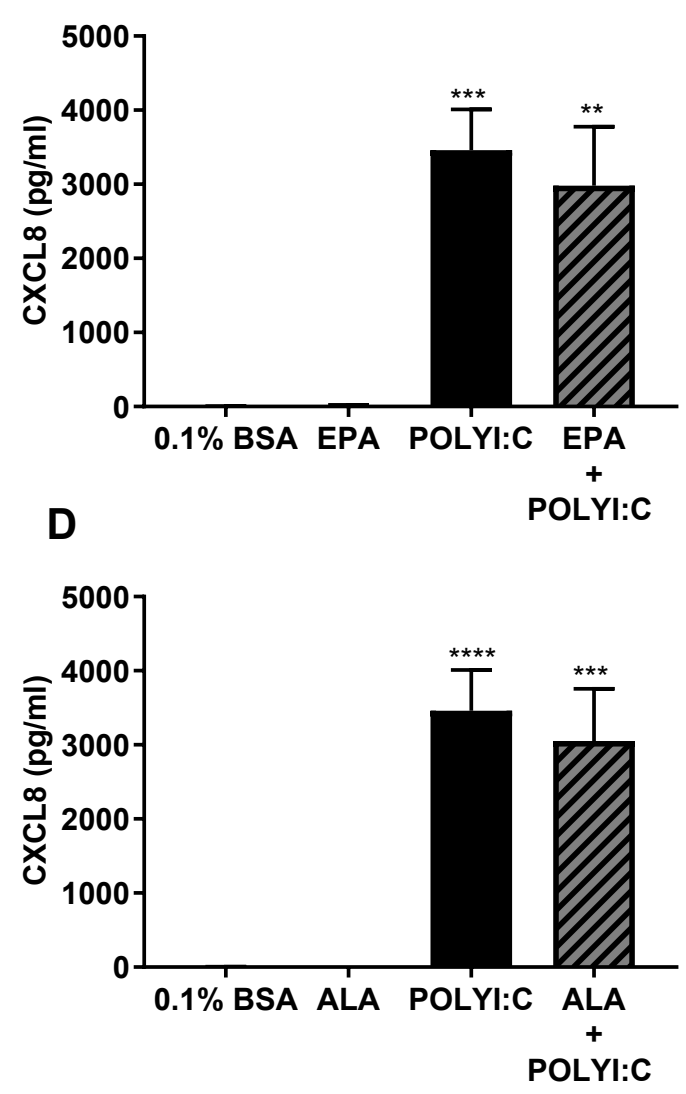

w-3 PUFAs do not suppress POLYI:C-induced IL-6 and CXCL8 release.

Human primary pulmonary fibroblasts $(n=5-9)$ (patients) were unstimulated or challenged with $\omega-3$ polyunsaturated fatty acids (PUFAs) eicosapentaenoic acid (EPA) (A, B) or $\alpha$-linolenic acid (ALA) (C, D) in $0.1 \%$ BSA-DMEM $(100 \mu \mathrm{M})$ for $4 \mathrm{~h}$ with or without the viral mimic polyinosinic:polycytidylic acid (POLYI:C) $(10 \mu \mathrm{g} / \mathrm{ml})$ for another $24 \mathrm{~h}$. Cell free supernatants were collected and IL-6 (A, C) and CXCL8 $(B, D)$ release was measured using ELISA. All data are represented as mean \pm standard error of the mean. All challenges are compared to control and challenges with POLYI:C are compared to challenge with POLYI:C alone, using a one-way ANOVA with a Bonferroni post-test. Significance is represented as $*(p<0.05),{ }^{* *}(p<0.01), * * *(p<0.001)$ or $* * * *(p<0.0001)$. 


\section{Supplementary Figure 2}

A

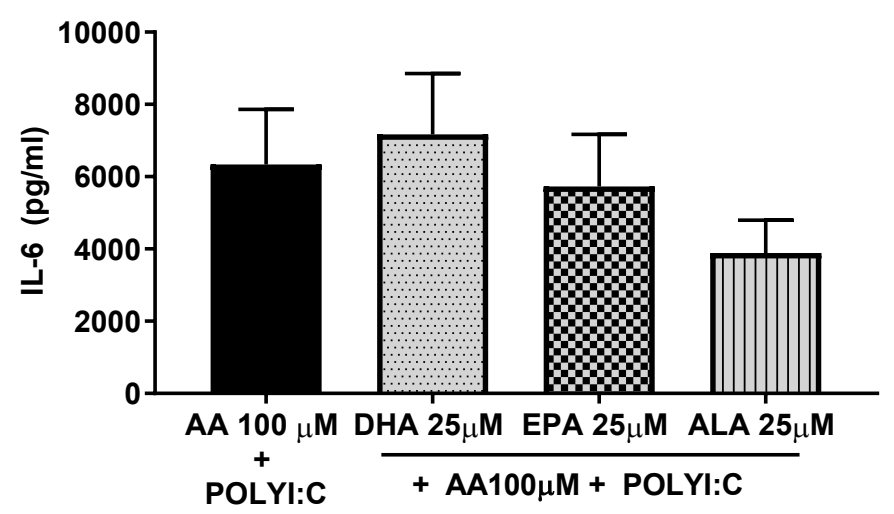

B

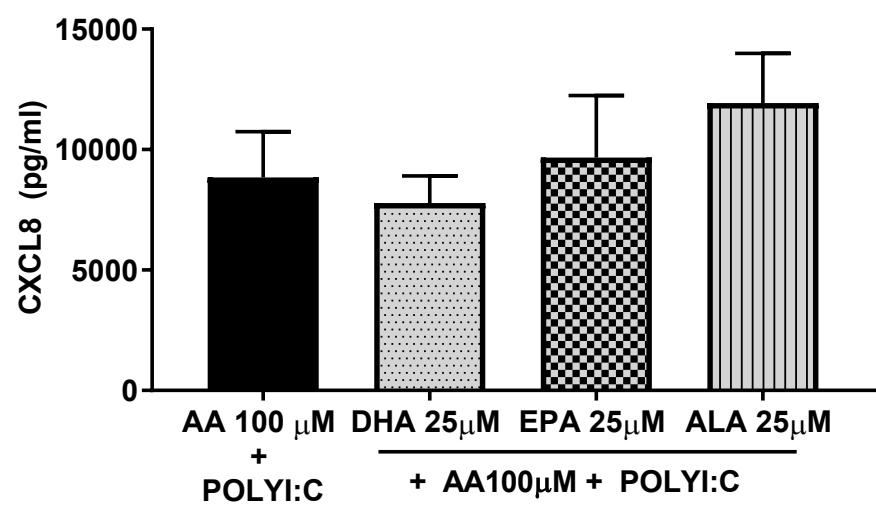

$\omega-3$ PUFAs do not suppress combined arachidonic acid and POLYI:C-induced IL-6 or CXCL8 release.

Human primary pulmonary fibroblasts $(n=9)$ (patients) were challenged with $\omega-6$ polyunsaturated

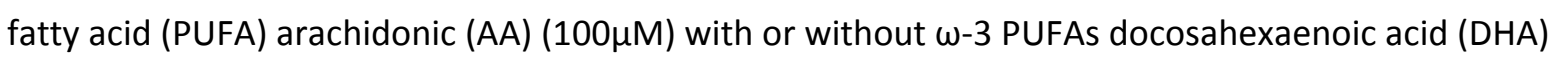
$(25 \mu \mathrm{M})$, eicosapentaenoic acid (EPA) $(25 \mu \mathrm{M})$ or $\alpha$-linolenic acid (ALA) $(25 \mu \mathrm{M})$ in $0.1 \%$ BSA-DMEM for

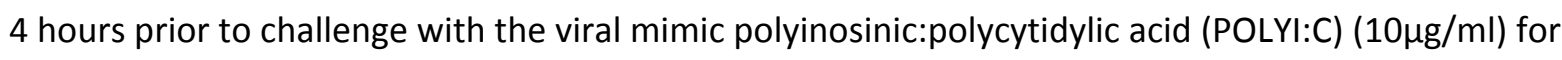
another 24h. Cell free supernatants were collected and IL-6 (A) and CXCL8 (B) release was measured using ELISA. All data are represented as mean \pm standard error of the mean. All challenges with $\omega-3$ PUFA are compared to their respective challenge without $\omega-3$ PUFA, using a one-way ANOVA with a Bonferroni post-test. There were no significant differences. 